\title{
Utilização da termografia infravermelha para detecção de focos de umidade em paredes internas de edificações
}

\author{
Use of infrared thermography for detection of moisture \\ sources in internal walls of buildings
}

\section{Cynthia Firmino dos Santos J oaquin Humberto Aquino Rocha Yêda Vieira Póvoas}

\section{Resumo

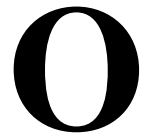

uso da termografia infravermelha tem se tornado alvo de estudos em várias áreas dentro da construção civil. Contudo, as pesquisas de detecção de presença de umidade em edificações ainda estão em desenvolvimento. O objetivo principal deste artigofoi estudar a viabilidadedo uso da termografia para a detecção de infiltrações devido a causas fortuitas em paredes internas. A metodologia consistiu na confecção de paredes de alvenaria de tijolos cerâmicos com diversas configurações de revestimento: sem revestimento, com gesso, gesso com tinta base látex, gessocom tinta base acrílica e gesso com cerâmica assentada com gesso cola. Em cada protótipo foi inserida uma tubulação furada a fim de simular vazamento. $\mathrm{O}$ avanço da infiltração foi verificado por meio de termogramas, por um período de $2 \mathrm{~h}$ com vazão constante, com 48 h e uma semana após o início da simulação. Os resultados encontrados confirmam que a termografia pode ser eficaz na deteç̧ão da região que contém o foco da infiltração oculta, desde que o revestimento não seja impermeável. Esse fato pode ser observado por meio dos gradientes térmicos produzidos. Nos revestimentos porosos $\Delta \mathrm{T}$ variou entre $2,6^{\circ} \mathrm{C}$ e $3,8^{\circ} \mathrm{C}$, e aqueles com características impermeáveis apresentaram $\Delta \mathrm{T}$ máximo de $2,2^{\circ} \mathrm{C}$, indicando a influência direta do tipo de revestimentono tempo de surgimento da mancha de umidade de forma aparente.

Palavras-chave:Termografia infravermelha. Revestimento. Infiltração. Umidade. Patologias na construção civil.

\section{Abstract}

The use of infrared thermography has become the theme of studies in several areas of the construction industry. However, research studies on detecting the presence of moisture in buildings are still under development. The main objective of this article was to study the feasibility of the use of thermography in the detection of infiltrations due to accidental causes in internal walls. The methodology consisted of the construction of masonry walls made of ceramic bricks with different coating configurations: uncoated, with plaster, plaster with latex paint, plaster with acrylic base paint and plaster with ceramic set with plaster glue. In each prototype, a drilled pipe was inserted to simulate water leaks. The infiltration progress was verified by means of thermograms, for a period of 2 hours with constant flow, and at 48 hours and one week after the beginning of the simulation. The results confirm that thermography may be effective in detecting the region containing the focus of hidden infiltration, provided the coating is not impermeable. This fact can be observed in the thermal gradients produced in the porous coatings, where $\Delta T$ ranged from 2.6 to $3.8^{\circ} \mathrm{C}$, whereas coatings with waterproof characteristics had a maximum $\Delta T$ of $2.2^{\circ} \mathrm{C}$. In addition, the type of coating directly influences the time required for the appearance of the moisture spot to become apparent.

Keywords: Infrared thermography. Coating. Infiltration. Moisture. Pathologies in civil construction. 


\section{Introdução}

Dentre as manifestações patológicas encontradas em uma edificação, as que envolvem umidade são as mais frequentes e difíceis de solucionar (JONOV; NASCIMENTO; PAULA E SILVA, 2013). A presença indesejada da água pode causar problemas que vão desde o desgaste de materiais e componentes da construção até a saúde e integridade dos usuários, o que pode ser bastante custoso em termos financeiros para a recomposição do dano (ALAM, 2016; ISRAEL, 2016; OLIVEIRA, 2013).

Para a detecção de infiltrações em edificações normalmente são utilizadas técnicas destrutivas, como a quebra de material, as quais promovem uma série de prejuízos como ruídos, produção de resíduos e poeira, afetando a estética da estrutura e a transitabilidade dos usuários. Nesse cenário, surge a necessidade do uso de ensaios não destrutivos para minimizar riscos e interferências na vida dos usuários (BARREIRA; FREITAS, 2007; BERNARDO, 2012; FREITAS; CARASEK; CASCUDO, 2014; ISRAEL, 2016).

Em relação às técnicas não destrutivas, existem instrumentos com os mais diversos princípios de funcionamento, como aqueles que utilizam a resistência elétrica, a radioatividade, a ressonância magnética nuclear, entre outros (MARINHO, 2014). Dentre eles, a termografia infravermelha, técnica que mede a radiação emitida pela superfície dos objetos, apresenta maiores vantagens para a inspeção, pois pode conseguir resultados rápidos sem a necessidade de contato físico com o objeto analisado e detectar danos não visíveis a olho nu, apresentando resultados em tempo real. Contudo, só é possível trabalhar com termografia se houver diferenças de temperatura. As imagens térmicas obtidas, termogramas, podem ser analisadas qualitativamente, por meio da visualização da heterogeneidade da temperatura na superfície do objeto estudado, ou quantitativamente, sendo necessário, nesse caso, considerar parâmetros ambientais no termógrafo (BARREIRA, 2004; TARPANI et al., 2009; AMARANTE; PONTES; MICHALOSKI, 2016; OLIVEIRA, 2013).

A termografia infravermelha é um método bastante utilizado na inspeção de obras civis, tendo cada vez mais aplicações, entre as quais podem ser citadas: detecção de vazamentos de ar em construções (BARREIRA; ALMEIDA; MOREIRA, 2017; MAROY et al., 2016); estudo de manifestações patológicas em fachadas (SILVA, 2012; BAUER; PAVÓN, 2017; BAUER et al., 2016; DE FREITAS; DE FREITAS; BARREIRA, 2014); estudo do desempenho térmico de edificações (FERRARINI et al., 2016; O'GRADY;
LECHOWSKA; HARTE, 2017); inspeção de pontes (REHMAN et al., 2016; ROCHA; PÓVOAS, 2017); estudo de manifestações patológicas e fenômenos associados a umidade em edificações (BARREIRA; ALMEIDA; DELGADO, 2016; LERMA; CABRELLES; PORTALÉS, 2011; OLIVEIRA, 2013; POBLETE; PASCUAL, 2007; BARREIRA; ALMEIDA; MOREIRA, 2017; LOURENÇO; MATIAS; FARIA, 2017), entre outros (ONUAGULUCHI; BANTHIA, 2017; AGGELIS et al., 2010; BAGAVATHIAPPAN et al., 2013).

O teste pode ser realizado ativamente, fornecendo calor a fim de aquecer o elemento e mostrar falhas, ou passivamente, capturando a temperatura natural da amostra causada pelo ambiente (MELRINHO, 2014). O método passivo é mais comum e foi utilizado, por exemplo, para a detecção de descolamento e umidade em revestimento cerâmico (LOURENÇO; MATIAS; FARIA, 2017) e umidade de capilaridade em edificações (BARREIRA; ALMEIDA; DELGADO, 2016). Contudo, alguns pesquisadores utilizaram a técnica ativa, a exemplo de Ham e Golparvar-Fard (2014), que estudaram os efeitos das condensações nas edificações; Grinzato et al. (2011), que mapearam a distribuição da umidade e identificaram áreas com conteúdo anormal de água em construções novas e antigas; e Melrinho, Matias e Faria (2015), que inspecionaram sistemas de impermeabilização de cobertas.

Em relação à detecção da presença de água em edificações, as alterações do teor de umidade produzem mudanças na temperatura superficial, podendo ser detectadas pela termografia devido a três fenômenos físicos (BARREIRA; ALMEIDA; DELGADO, 2016; EDIS; FLORES-COLEN; BRITO, 2014):

(a) resfriamento evaporativo na área úmida no processo de evaporação há uma diminuição da temperatura superficial, pois se trata de uma reação endotérmica;

(b) resistência térmica diminuída: o fluxo de calor é maior em uma massa úmida do que em uma massa seca gerando um padrão térmico heterogêneo; e

(c) aumento da capacidade de armazenamento de calor do material úmido: a temperatura superficial de uma massa úmida responde de forma mais lenta a mudanças na temperatura ambiental do que a temperatura superficial de uma massa seca.

No entanto, mesmo tendo sido apresentado muitos trabalhos para detecção de umidade em edificações, 
não existem procedimentos padronizados e ainda se tem algumas incertezas quanto a seu alcance ao tipo de umidade. Normalmente detecta-se a presença de umidade em uma edificação após o surgimento de forma visível das manifestações patológicas como eflorescência, destacamento, ou presença de bolor, sendo esses casos indesejáveis (EDIS; FLORESCOLEN; BRITO, 2014). Nesse contexto, o presente artigo tem como objetivo avaliar a termografia infravermelha como uma técnica aplicada na detecção de infiltrações devido a causas acidentais em paredes internas com revestimentos de diferentes porosidades, ainda que em fase embrionária, contribuindo para o auxílio na tomada de decisão frente às manifestações patológicas encontradas nas construções, além de apresentar as limitações da técnica.

\section{Método}

Uma parte da metodologia foi baseada na pesquisa realizada por Alam (2016), por meio da qual o autor confeccionou, em laboratório, paredes com diferentes tipos de tijolos cerâmicos e mesmo revestimento com a inserção de um tubo de PVC de $20 \mathrm{~mm}$ furado, para simular um vazamento acidental. Para este trabalho, foram construídas paredes com tijolos de (19 cm x19 cm x19cm) e diferentes tipos de revestimento aplicado apenas na parte frontal da parede, que é a porção a ser analisada. Foi inserida tubulação furada de PVC de $25 \mathrm{~mm}$, tamanho diferente daquele utilizado por Alam (2016), devido a sua fixação na alvenaria ter sido sem argamassa.

\section{Confecção dos protótipos de paredes}

Foram elevadas cinco paredes, sendo uma de (80 $\mathrm{cm}$ x $60 \mathrm{~cm}$ ), Figura 1, e as quatro restantes de (100 $\mathrm{cm} \times 100 \mathrm{~cm}$ ), Figura 2. Os protótipos foram construídos com tamanhos diferentes devido ao seus posicionamentos no laboratório. O Quadro 1 apresenta as características dos protótipos.

\section{Figura 1 - Parede A: (a) foto; (b) desenho esquemático}

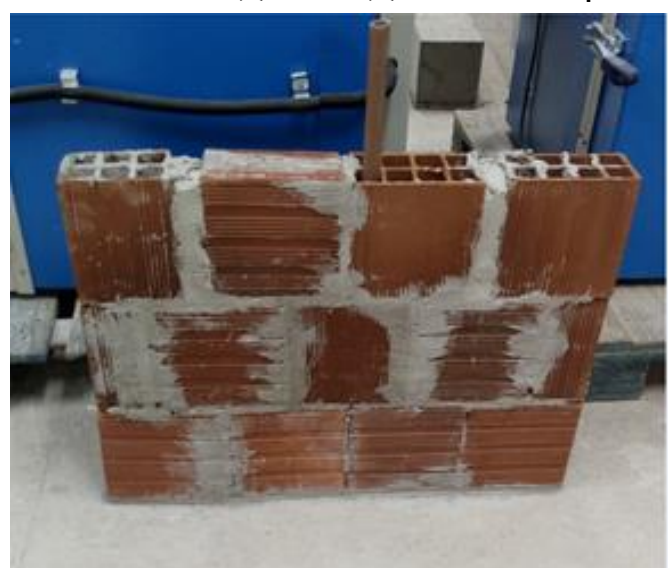

(a)

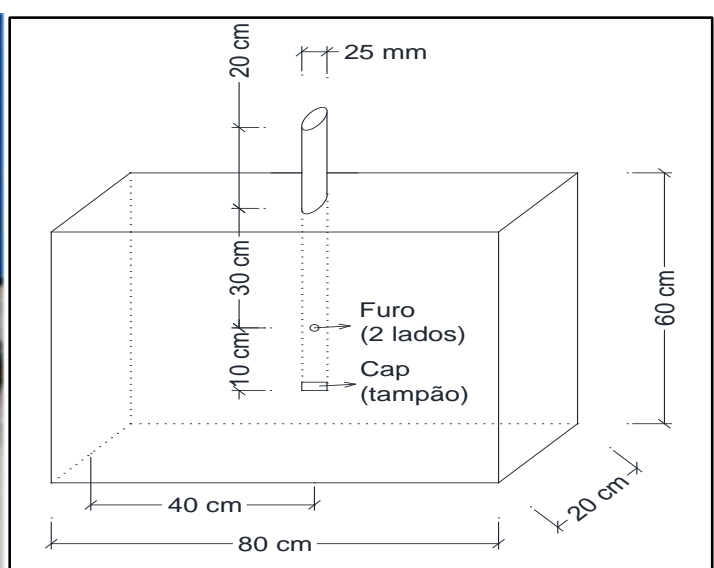

(b)

Figura 2 - Paredes B, C, D e E: (a) foto; (b) desenho esquemático

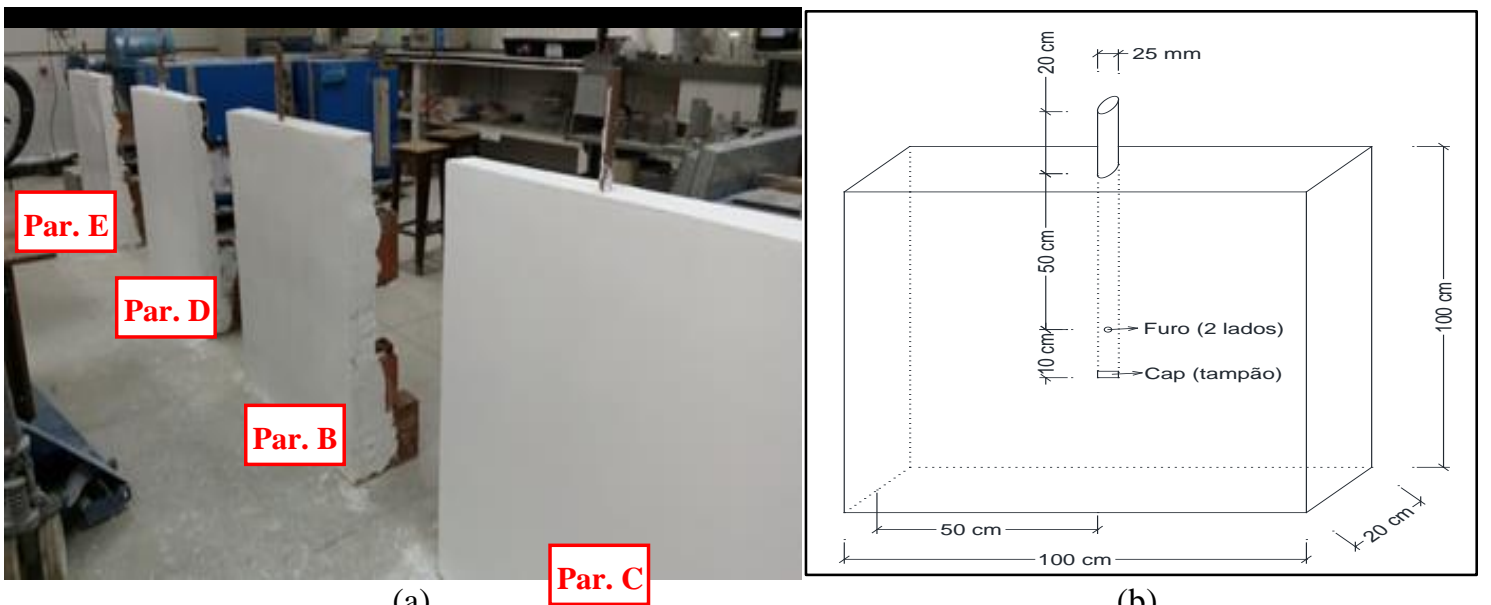

(a)

(b) 
Quadro 1 - Descrição dos protótipos construídos

\begin{tabular}{|c|l|c|}
\hline Protótipo & \multicolumn{1}{|c|}{ Características } & Dimensões \\
\hline Parede A (Par. A) & De referência, sem revestimento & \multirow{2}{*}{$(80 \mathrm{~cm}$ x 60 cm) } \\
\cline { 1 - 2 } Parede B (Par. B) & Revestida com gesso & \multirow{2}{*}{$(100 \mathrm{~cm}$ x $100 \mathrm{~cm})$} \\
\cline { 1 - 2 } Parede C (Par. C) & Revestida com gesso e tinta base látex & \\
\cline { 1 - 2 } Parede D (Par. D) & Revestida com gesso e tinta base acrílica & \\
\cline { 1 - 2 } Parede E (Par. E) & $\begin{array}{l}\text { Revestida com gesso mais placa cerâmica } \\
\text { assentada com gesso cola }\end{array}$ & \\
\hline
\end{tabular}

Os tijolos por onde o tubo de PVC passou foram assentados na vertical de forma que a tubulação utilizada para simular o vazamento fosse inserida nos furos do bloco sem haver a necessidade de quebra para a sua inserção. O tubo de PVC foi perfurado com dois orifícios paralelos, executados a $10 \mathrm{~cm}$ de distância do fundo do tampão, de forma a ficarem centralizados em relação ao eixo vertical nos protótipos.

Os tijolos utilizados para a confecção das paredes foram do tipo cerâmico com dimensões de $(19$ cm x $19 \mathrm{~cm}$ x $9 \mathrm{~cm}$ ). Foi realizado o ensaio de absorção d'água conforme recomendação do anexo $\mathrm{B}$ da NBR 15270-3 (ABNT, 2005b). A absorção encontrada foi de $13 \%$, valor que está dentro do limite estabelecido na NBR 15270-1 (ABNT, 2005a). A argamassa adotada para a elevação da alvenaria foi do tipo industrializada, coma relação água/materiais secos indicada pelo fabricante, 1:4.

Foi escolhido um gesso para revestimento do mercado, com a relação água/gesso de 1:1,4, indicada pelo fabricante. Para a pintura dos protótipos C e D foram utilizados dois tipos de tintas: uma de base látex (fosco aveludada) e uma de base acrílica (semibrilho), ambas de cor branco neve.

Foram utilizadas placas cerâmicas tipo “B”, com dimensões de (420 mm x 420mm x 7,5 mm), consideradas do grupo de absorção de água Bllb (6\% a 10\%) de cor branco gelo. Para o rejuntamento foi utilizada uma argamassa industrializada para uso interno e externo. Foram seguidas as recomendações do fabricante quanto à medida de água necessária à mistura, relação água/argamassa de 1:4. Para o assentamento das placas cerâmicas foi usado o gesso cola, devido a sua rapidez no tempo de cura. A adição de água se deu de acordo com as instruções do fabricante, apresentada na embalagem, com relação água/gesso cola de 1:1,4.

\section{Termografia infravermelha}

A câmera termográfica utilizada para o estudo foi do modelo FLIR E-60. O Quadro 2 mostra algumas de suas especificações.
Para possibilitar o uso da termografia, alguns parâmetros foram determinados:

(a) a temperatura refletida foi determinada por meio do uso do papel alumínio amassado (devido a sua alta refletividade) posicionado no protótipo estudado. Foi tomado um termograma, utilizando os parâmetros de emissividade igual a 1,0 e distância igual a 0 , tanto da parede quanto da folha de alumínio para medição da sua temperatura, que resulta na temperatura refletida;

(b) a emissividade do material foi determinada pelo método da fita preta, que consiste em fixar sobre a superfície do objeto analisado uma fita de emissividade conhecida, de 0,95, conforme informado pelo fabricante. Depois é medida a temperatura da fita (temperatura padrão) e ajustada a emissividade da câmera até que a temperatura do objeto, sem a fita, a fim de obter a mesma temperatura de referência, determinando a emissividade do objeto a ser analisado (LOURENÇO; MATIAS; FARIA, 2017). Nos protótipos estudados o valor da emissividade variou entre 0,93 e 0,95;

(c) determinação da umidade relativa do ar (U.R.), em \%, e da temperatura ambiente (T), em ${ }^{\circ} \mathrm{C}$, por meio de um termohigrômetro. A temperatura ambiente foi de $(27 \pm 2)^{\circ} \mathrm{C}$ e a umidade

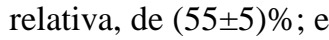

(d) a distância do equipamento até o protótipo foi de 2 metros para a Parede A e de 3 metros para as Paredes B, C, D e E, valores diferentes devido à variação de tamanho das paredes, sendo utilizado um suporte de madeira para manter a distância e o foco.

A alimentação de água para a simulação do vazamento se deu por meio de uma mangueira ligada na torneira, durante 2 horas, com vazão aproximada de $10,67 \mathrm{~cm}^{3} / \mathrm{s}$ para a parede de menor dimensão e $9,04 \mathrm{~cm}^{3} / \mathrm{s}$ para as demais, com uma temperatura aproximada de $28{ }^{\circ} \mathrm{C}$. O ensaio foi realizado dentro do laboratório onde o aparelho de ar condicionado estava ligado, para manter uma temperatura ambiente constante durante o ensaio e avaliar a temperatura dos protótipos. 
A quantidade de dias necessária para a execução das camadas dos protótipos bem como para o início do ensaio está descrita no Quadro 3.

Obedecendo ao tempo de cura das etapas de construção dos protótipos, foram simuladas as infiltrações e realizadas as leituras termográficas de acordo com os tempos descritos no Quadro 4, com o auxílio de um cronômetro. Também foi anotado em que tempo as manchas visíveis apareceram (quando apareceram). Os protótipos não foram ensaiados no mesmo dia nem na ordem de construção; contudo, em alguns casos, uma determinada etapa de uma parede coincidiu com a de outra.

A medição da temperatura superficial foi realizada nos protótipos nos locais nomeados por SP1, SP2, SP3, SP4 e SP5 e indicados na Figura 3. SP1 coincide com o furo realizado no tubo.

Quadro 2 - Especificações da FLIR E-60

\begin{tabular}{|l|l|}
\hline \multicolumn{1}{|c|}{ Características da câmera } & \multicolumn{1}{c|}{ FLIR E-60 } \\
\hline Resolução IR & $320 \times 240$ pixels \\
\hline Sensibilidade térmica & $<0,05^{\circ} \mathrm{C}$ \\
\hline Precisão & $\pm 2^{\circ} \mathrm{C} \mathrm{ou} \pm 2 \%$ de leitura \\
\hline Faixa de temperatura & $-20^{\circ} \mathrm{C}$ a $650^{\circ} \mathrm{C}$ \\
\hline
\end{tabular}

Fonte: FLIR (2013).

Quadro 3 - Tempo necessário para a execução das camadas dos protótipos e início do ensaio

\begin{tabular}{|c|l|c|c|}
\hline Protótipo & \multicolumn{1}{|c|}{ Camadas } & $\begin{array}{c}\text { Intervalo de } \\
\text { execução das } \\
\text { camadas (dias) }\end{array}$ & $\begin{array}{c}\text { Tempo de finalização do } \\
\text { protótipo até a inserção } \\
\text { de água (dias) }\end{array}$ \\
\hline Parede A & Apenas alvenaria & - & 40 \\
\hline Parede B & Alvenaria + gesso & $21+9$ & 18 \\
\hline Parede C & Alvenaria + gesso + tinta PVA & $21+9$ & 11 \\
\hline Parede D & Alvenaria + gesso + tinta acrílica & $21+7$ & 8 \\
\hline Parede E & Alvenaria + gesso + cerâmica + rejunte & $21+7+2$ & 8 \\
\hline
\end{tabular}

Quadro 4 - Tempos para o ensaio termográfico

\begin{tabular}{|c|l|}
\hline Leitura & Momento \\
\hline 01 & Alvenaria seca \\
\hline \multicolumn{2}{|c|}{ Torneira foi aberta } \\
\hline 02 & 5 minutos após a inserção de água \\
\hline 03 & 10 minutos após a inserção de água \\
\hline 04 & 15 minutos após a inserção de água \\
\hline 05 & 20 minutos após a inserção de água \\
\hline 06 & 25 minutos após a inserção de água \\
\hline 07 & 30 minutos após a inserção de água \\
\hline 08 & 40 minutos após a inserção de água \\
\hline 09 & 50 minutos após a inserção de água \\
\hline 10 & 1 hora após a inserção de água \\
\hline 11 & 1 hora e 20 minutos após a inserção de água \\
\hline 12 & 1 hora e 40 minutos após a inserção de água \\
\hline 13 & 2 horas após a inserção de água \\
\hline \multicolumn{2}{|c|}{ Torneira foi fechada } \\
\hline 14 & 48 horas após a inserção de água \\
\hline 15 & 1 semana após a inserção de água \\
\hline
\end{tabular}


Figura 3 - Localização dos pontos de medição da temperatura superficial: (a) Parede A; (b) Paredes B, C, D e E

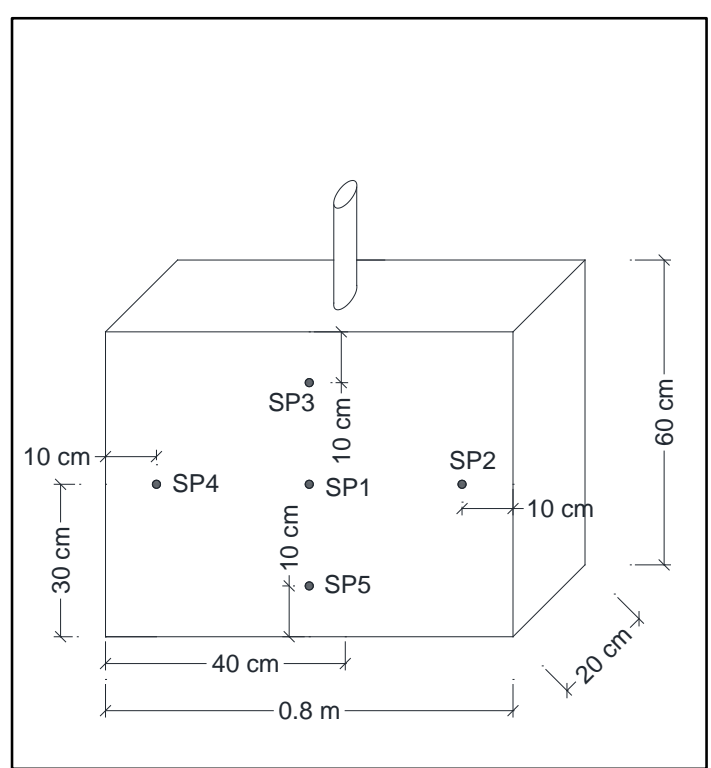

(a)

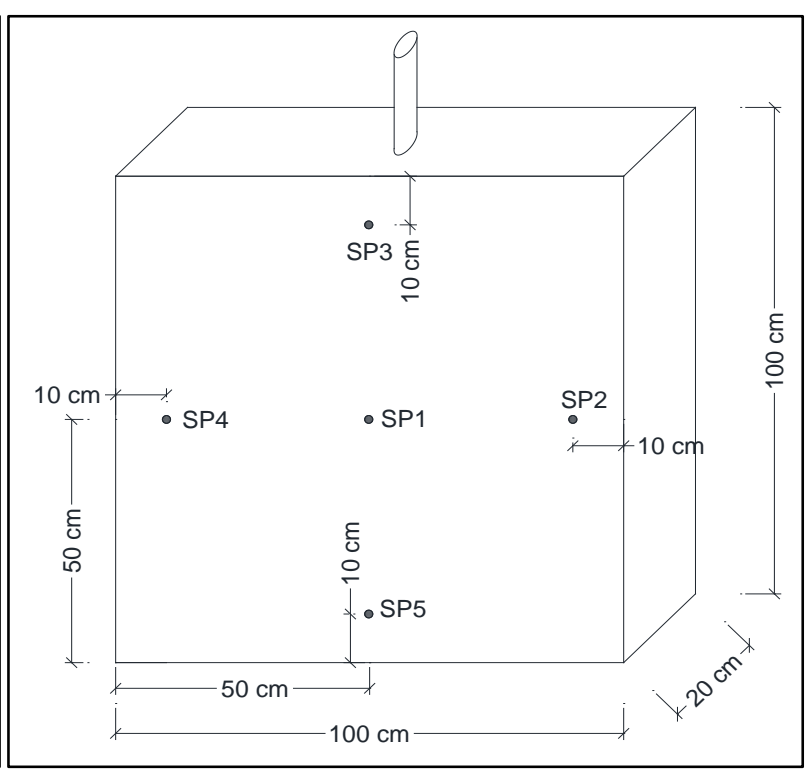

(b)
Para auxiliar o tratamento e edição dos termogramas utilizou-se o software FLIR Tools. Para a análise dos resultados, comparou-se uma região não afetada pela umidade (área de referência) com uma que apresentava manifestações patológicas características de infiltração, representada como um contraste térmico, expressa na Equação 1.

$\Delta \mathrm{T}=\mathrm{Ts}-\mathrm{Tu}$

Eq. 1

Onde:

$\Delta \mathrm{T}=$ Diferença de temperatura entre a área seca e a área afetada pela umidade $\left({ }^{\circ} \mathrm{C}\right)$;

Ts = Temperatura da área seca $\left({ }^{\circ} \mathrm{C}\right)$; e

$\mathrm{Tu}=$ Temperatura da zona afetada pela umidade $\left({ }^{\circ} \mathrm{C}\right)$.

Ts e Tu foram escolhidos dentre os pontos SP1, SP2, SP3, SP4 e SP5 de forma que, para o mesmo protótipo, essas regiões estivessem localizadas no mesmo lugar nas imagens termográficas recolhidas durante o ensaio. Contudo, para diferentes protótipos, as áreas secas e úmidas a serem consideradas poderiam mudar.

\section{Análise e discussão dos resultados}

\section{Parede A (de referência, sem revestimento)}

Quando a parede estava seca as temperaturas de todos os pontos estavam próximas, variando de $27,5^{\circ} \mathrm{C}$ a $27,8^{\circ} \mathrm{C}$, demonstrando ausência de infiltração, informação que pode ser ratificada com a análise do termograma e da fotografia convencional apresentados na Figura 4.

Na Figura 5a apresenta-se o termograma depois de 5 minutos que a água começou a ser inserida. As áreas frias são apresentadas com a cor roxa e as mais quentes com a cor amarela.

A mancha de umidade a olho nu apareceu 50 segundos após a inserção de água (Figura 5b). Esse fato mostra a suscetibilidade do aparecimento das manchas de infiltração quando a alvenaria não possui revestimento, fato semelhante ao resultado encontrado por Alam (2016).

O ponto SP1 não apareceu esfriando com o tempo pelo fato de o teste ter sido realizado em um dia ensolarado na região nordeste do país. A instalação hidráulica que liga a torneira ao reservatório de água superior foi construída de forma aparente, o que fez a água da torneira sair aquecida. Sob a influência das condições ambientais, à medida que a infiltração aflorou na superfície do protótipo, a zona afetada pela água apresentou-se mais fria no termograma.

Normalmente as áreas afetadas pela umidade são apresentadas com temperatura mais baixa que as áreas secas, devido ao fenômeno de evaporação superficial. Contudo, pode acontecer o contrário por causa da alta inércia térmica (capacidade que o material tem de armazenar calor) da água quando comparada com os materiais de construção secos, conforme dito por Grinzato et al. (2011) e Melrinho, Matias e Faria (2015). 
Figura 4 - Parede A seca: (a) termograma; (b) fotografia

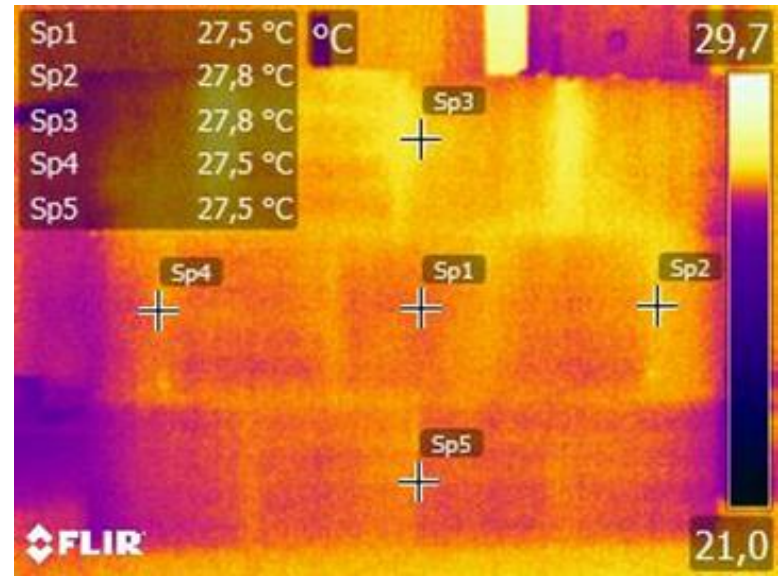

(a)

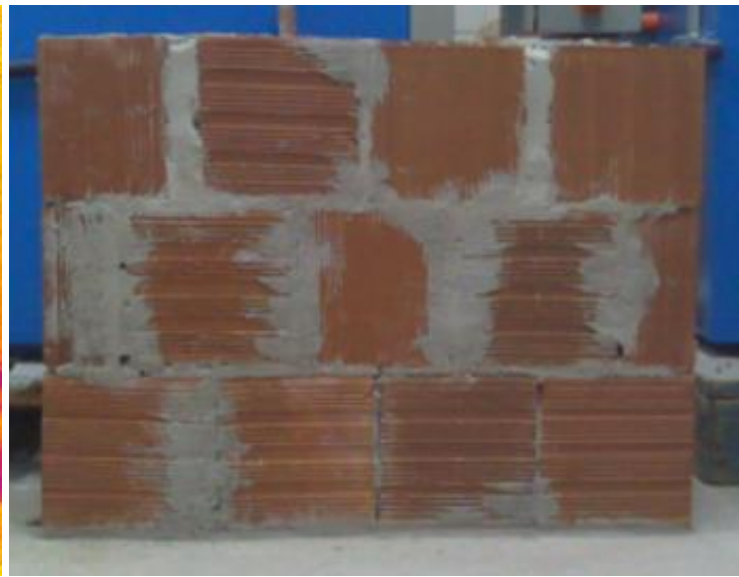

(b)

Figura 5 - Leitura 5 minutos após a inserção de água na Parede A: (a) termograma; (b) fotografia

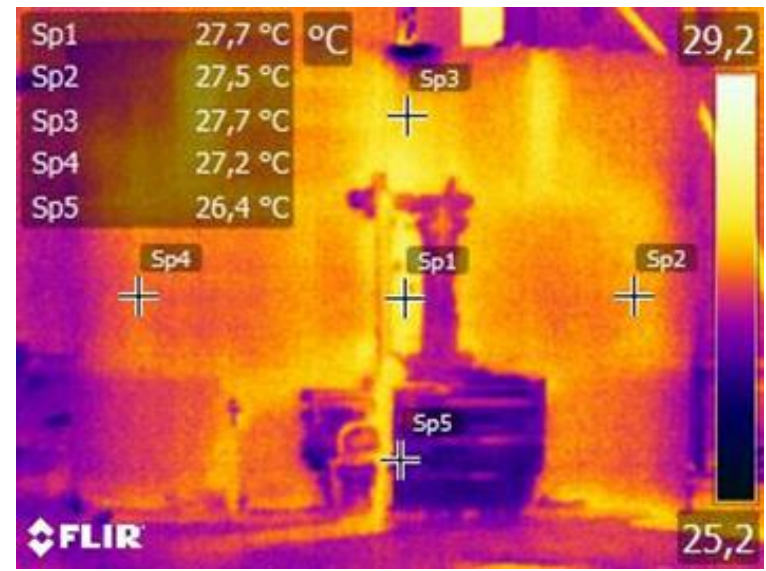

(a)

Com o intuito de analisar o comportamento da secagem com o tempo, 48 horas e 1 semana, foi adotado como ponto de medição da temperatura da área seca (Ts) o ponto "SP2", e para a área afetada pela umidade (Tu) o ponto "SP5". Foi construído um gráfico com os gradientes de temperatura $(\Delta \mathrm{T})$ ao longo do tempo (Figura 6).

Os gradientes de temperatura, durante o período em que a água incidiu, permaneceram quase constantes até 2 horas de ensaio. $\mathrm{O}$ valor máximo $(\Delta \mathrm{T}=3,2$ ${ }^{\circ} \mathrm{C}$ ) foi atingido após 48 horas (Figura 7). O menor valor $\left(\Delta \mathrm{T}=0,2^{\circ} \mathrm{C}\right)$ se deu após 1 semana, quando o protótipo aparentou estar quase seco (Figura 8).

Pode se ver que as imagens convencionais (Figura 7b e Figura 8b) não mostraram com nitidez a diferença entre a porção úmida e a seca, mas nos termogramas (Figuras 7a e 8a) destacaram com clareza o gradiente térmico, apontando a capacidade da termografia na detecção de umidade pouco visível.

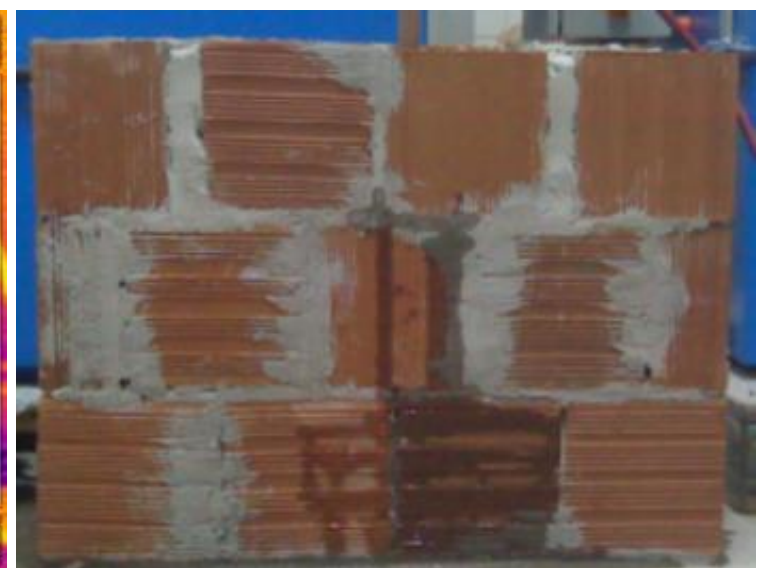

(b)

As manchas se assemelham às características que Klüppel e Santana (2005) descreveram da umidade oriunda de falha em tubulação, principalmente por ser o centro mais frio e a umidade decrescer em todas as direções.

A Figura 9 mostra o gráfico com as temperaturas dos pontos SP1, SP2, SP3, SP4 e SP5 e a temperatura ambiente de acordo com os tempos de leitura.

Observa-se que as temperaturas dos pontos estudados eram próximas antes da abertura da torneira, mostrando um equilíbrio térmico da superfície da parede. Durante as primeiras 2 horas de ensaio as temperaturas dos pontos apresentaram diferenças na temperatura, devido à presença de água. Após 48 horas, SP1 (local do furo) e SP5 se resfriaram. No final do teste (1 semana), há tendência a equilíbrio térmico entre a parede e o ambiente. 


\section{Parede B (revestida com gesso)}

Antes de a água começar a ser introduzida na parede, as temperaturas de SP1, SP2, SP3, SP4 e SP5 tinham valores bem próximos, variando de 25,0
${ }^{\circ} \mathrm{C}$ a $25,4{ }^{\circ} \mathrm{C}$, com amplitude de $0,4^{\circ} \mathrm{C}$. Observandose o termograma desse momento percebe-se que não há sinais aparentes da presença de umidade (Figura 10a).

Figura 6 - Diferença de temperatura entre "SP2" e "SP5" na Parede A

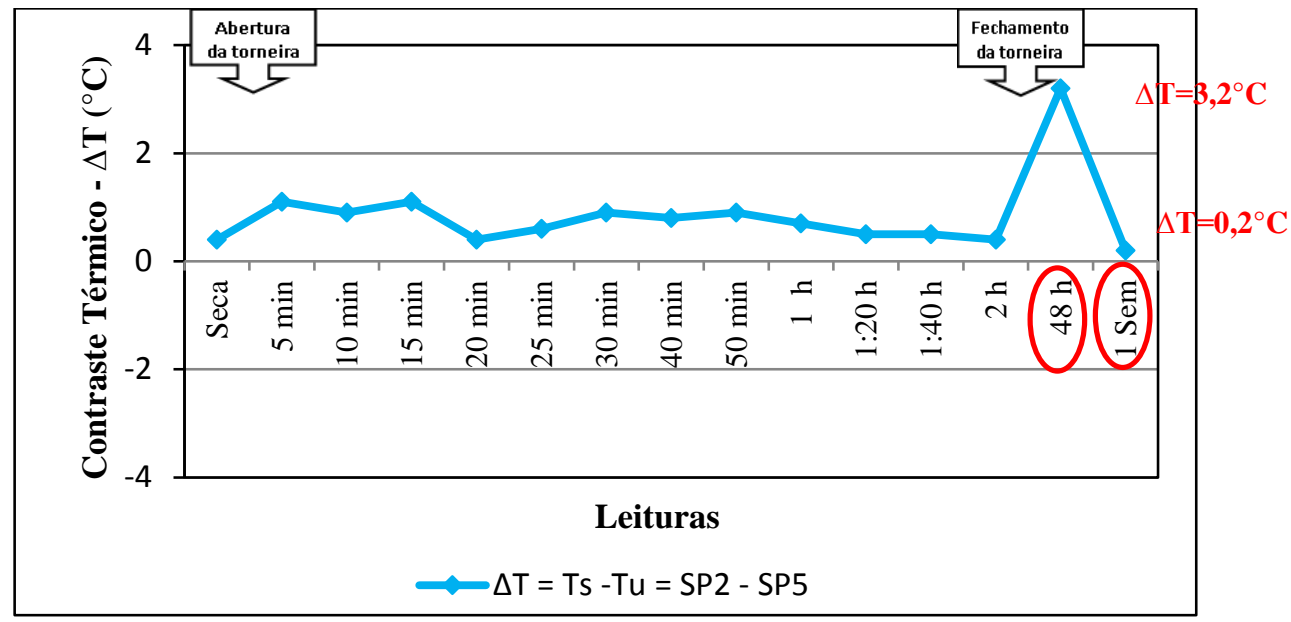

Figura 7 - Leitura 48 horas após a inserção de água na Parede A: (a) termograma; (b) fotografia

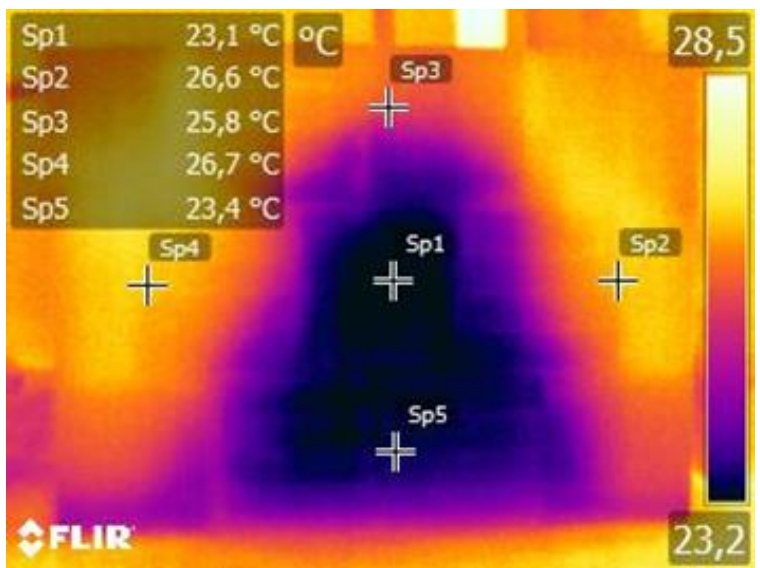

(a)

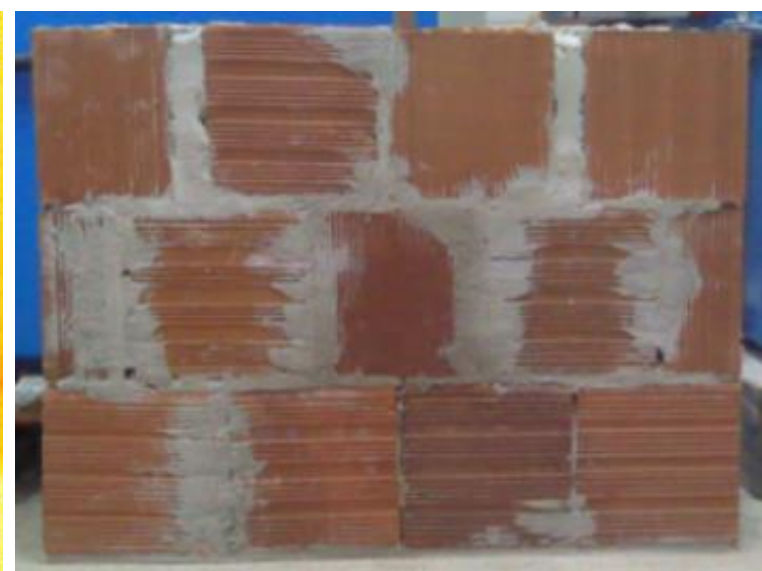

(b)

Figura 8 - Leitura 1 semana após a inserção de água na Parede A: (a) termograma; (b) fotografia

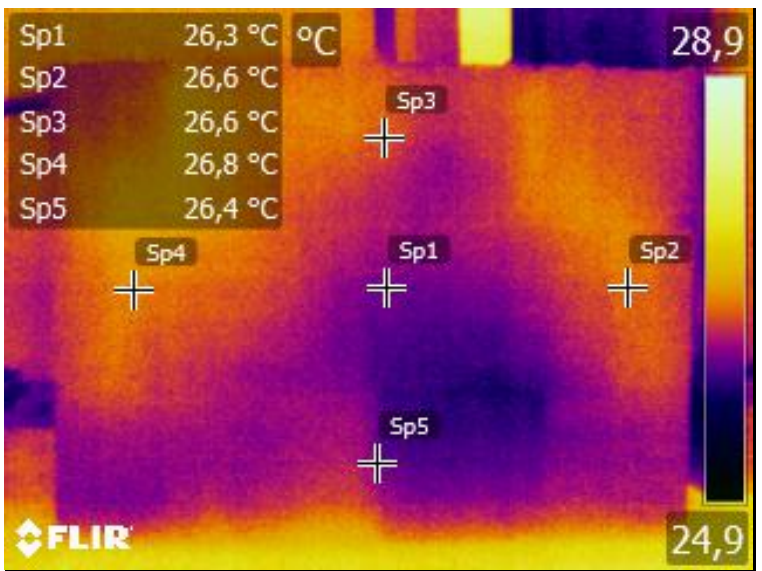

(a)

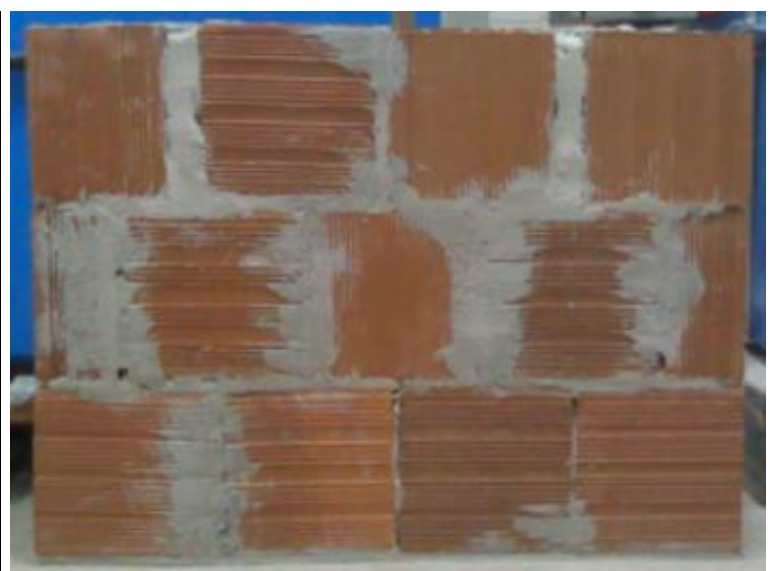

(b) 
Figura 9 - Temperatura ambiente e dos pontos estudados da Parede A

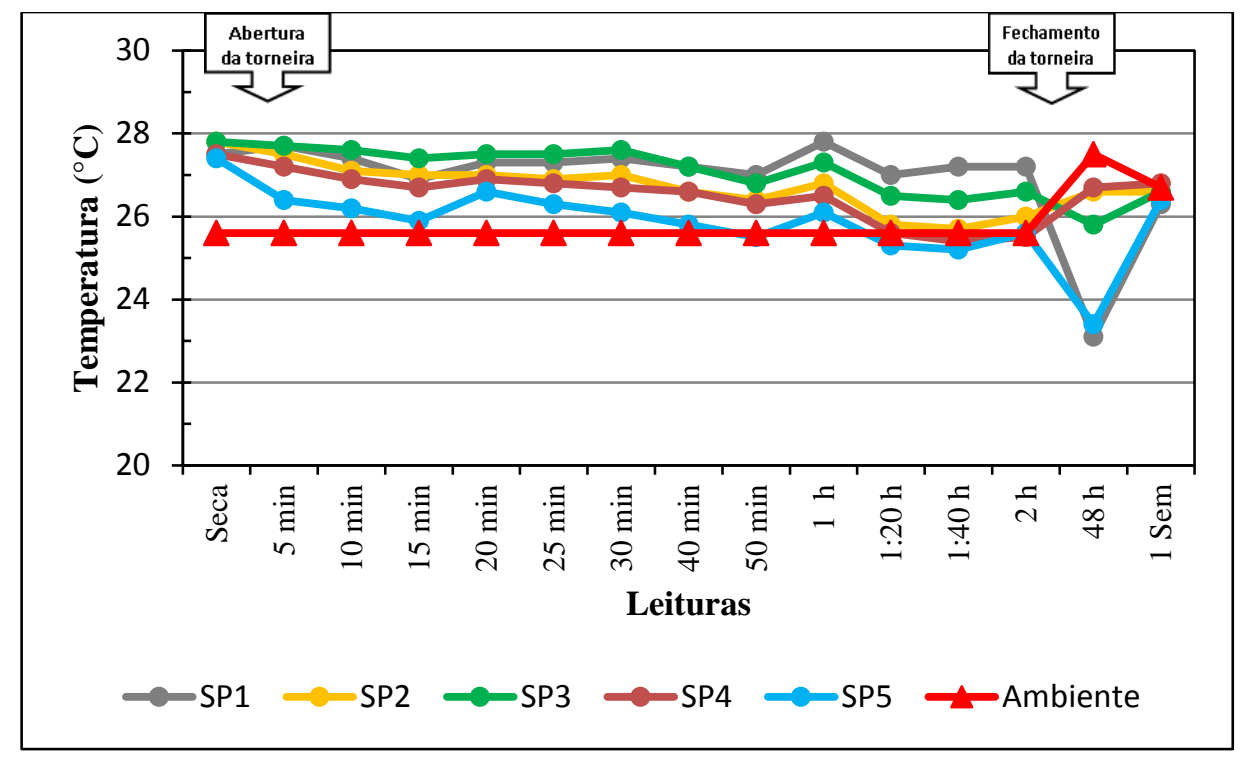

Figura 10 - Parede B seca: (a) termograma; (b) fotografia

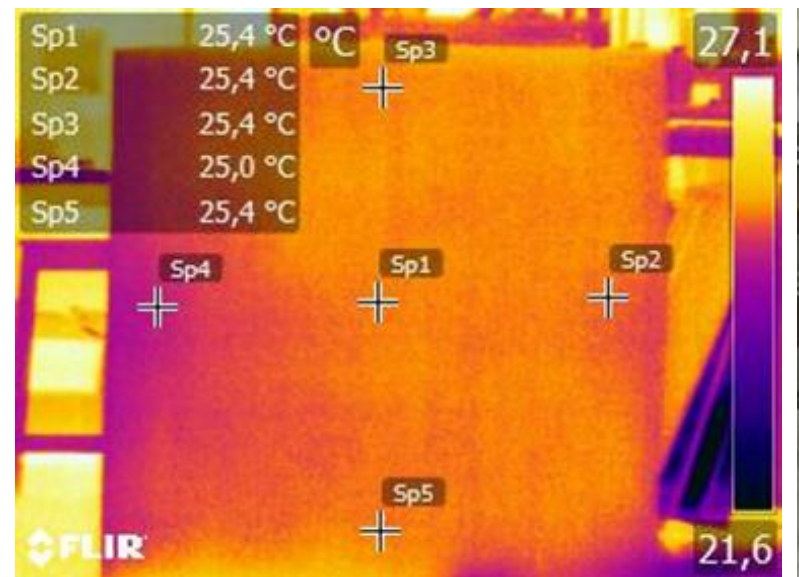

(a)

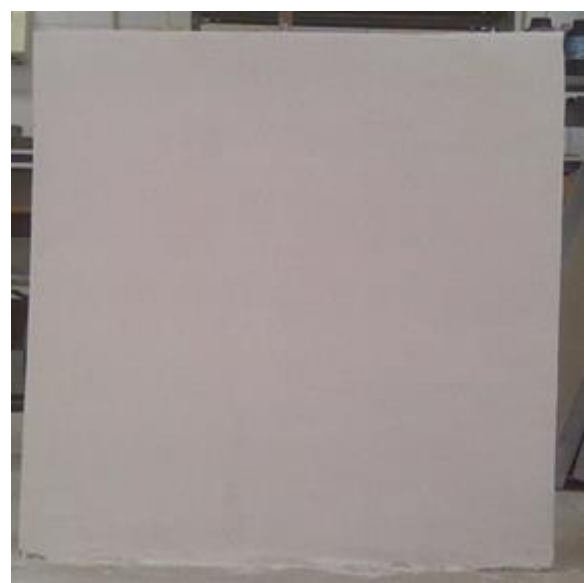

(b)
Na Figura 11a apresenta-se o termograma 5 minutos após a torneira ser aberta, onde há presença de água, uma vez que esta apareceu visível a olho nu 1 minuto e 9 segundos após o início do ensaio. Em relação à Parede $\mathrm{A}$, o tempo necessário para o surgimento dos primeiros sinais de água foi maior devido à proteção provocada pela camada de gesso. SP1 apresentou temperatura mais alta em consequência da maior inércia térmica da água em relação ao gesso, provocada pela saída de água quente da torneira.

As manchas de umidade apareceram de forma aleatória, inclusive não iniciando seu surgimento pelo local do orifício da tubulação, que seria a região mais provável de origem da manifestação patológica. Conforme o tempo passa o espalhamento da água avança primeiro pelas juntas de argamassa, que por ser mais porosa que o tijolo se torna o caminho mais fácil. O mesmo fenômeno foi observado por Cabaça (2002).

Com SP2 representando as áreas secas e SP1 as áreas úmidas, os gradientes térmicos $(\Delta \mathrm{T})$ foram reunidos na Figura 12.

$\mathrm{O}$ menor valor de gradiente térmico $\left(\Delta \mathrm{T}=0{ }^{\circ} \mathrm{C}\right)$ se deu quando o protótipo estava seco. $\mathrm{O}$ maior valor de $\Delta \mathrm{T}\left(3,8^{\circ} \mathrm{C}\right)$ aconteceu aos 15 minutos. A água aquecida produziu valores de $\Delta \mathrm{T}$ negativos durante as 2 horas de ensaio. Após as 48 horas, com o esfriamento e espalhamento da água, a nitidez do contraste térmico entre áreas secas e úmidas foi melhorada (Figura 13a). No fim do experimento (Figura 14a), com a secagem, $\Delta \mathrm{T}$ diminuiu naturalmente, mas ainda é possível observar as áreas afetadas pela umidade. 
Figura 11 - Leitura 5 minutos após a inserção de água na Parede B: (a) termograma; (b) fotografia

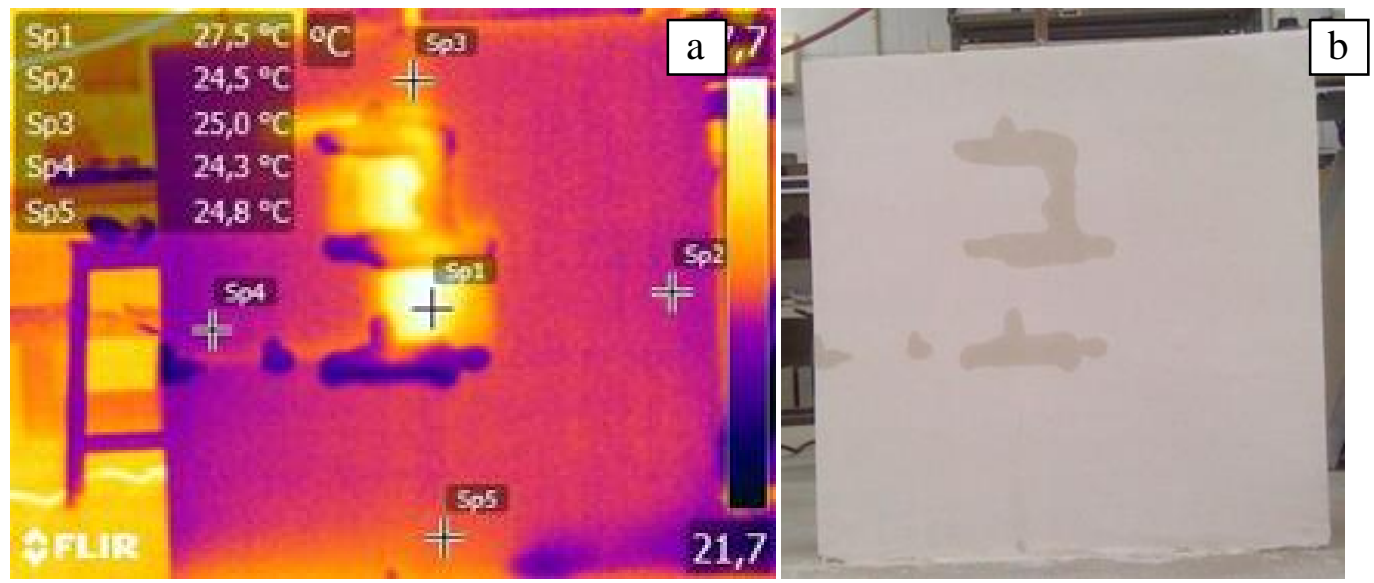

Figura 12 - Diferença de temperatura entre "SP2" e "SP1" na Parede B

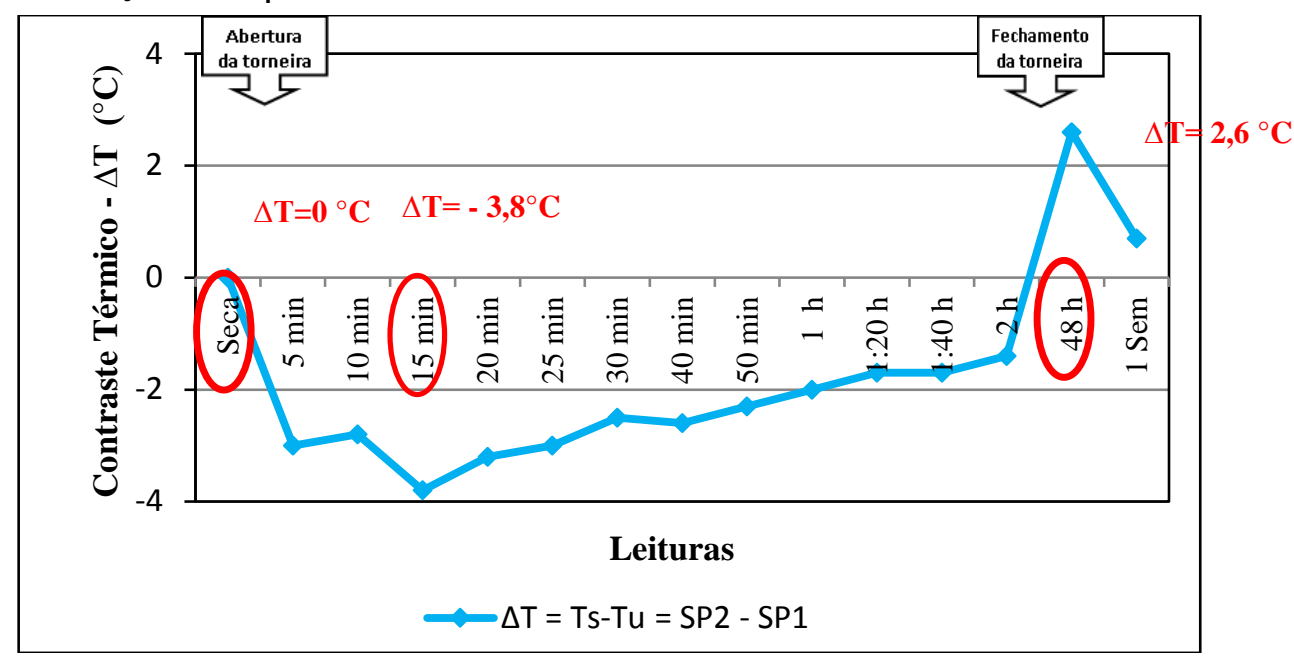

Figura 13 - Leitura 48 horas após a inserção de água na Parede B: (a) termograma; (b) fotografia

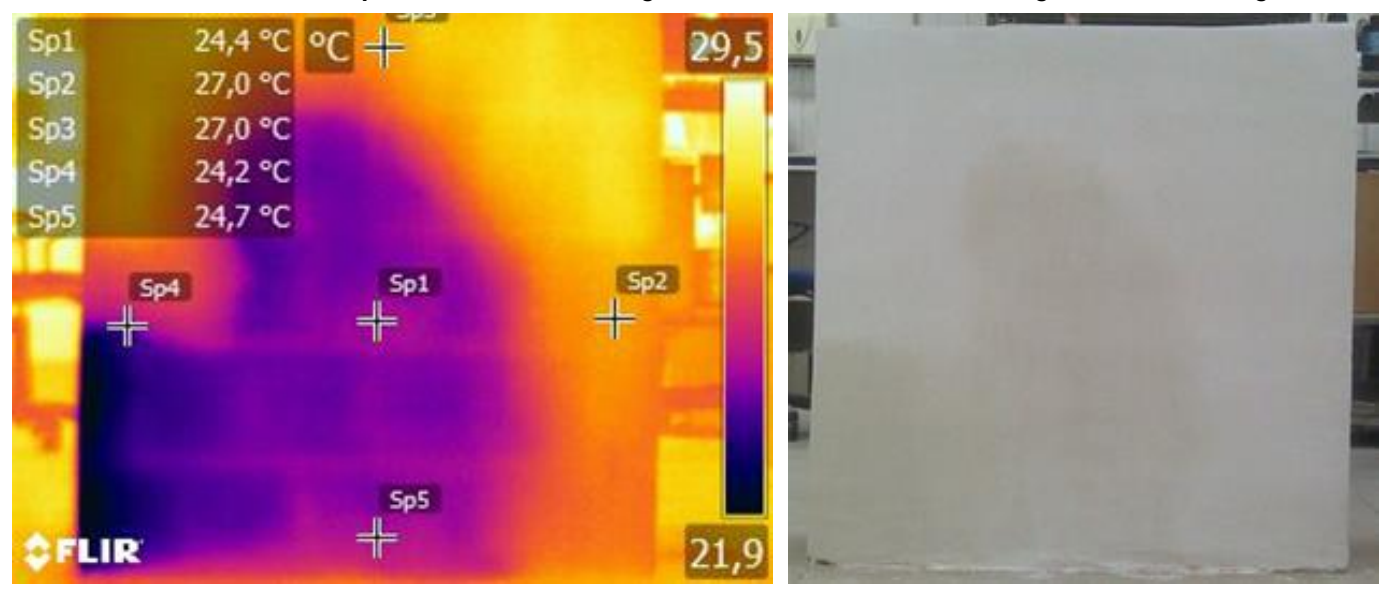


Figura 14 - Leitura 1 semana após a inserção de água na Parede B: (a) termograma; (b) fotografia

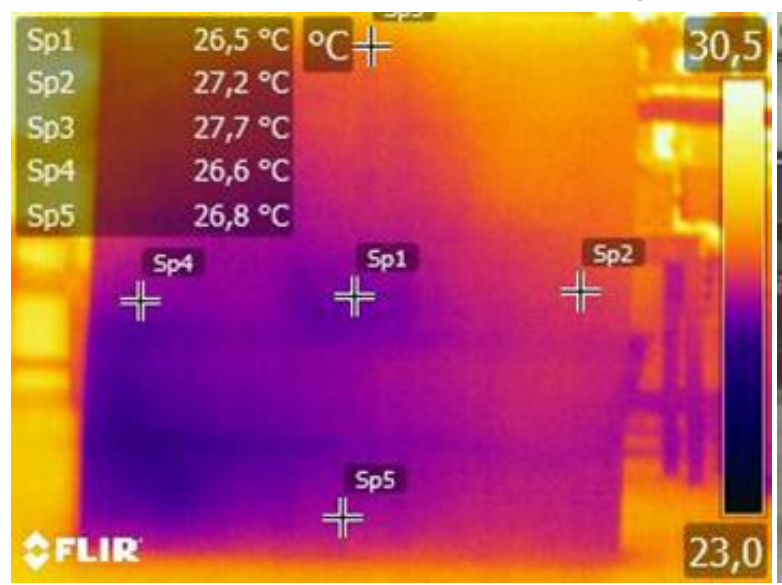

(a)

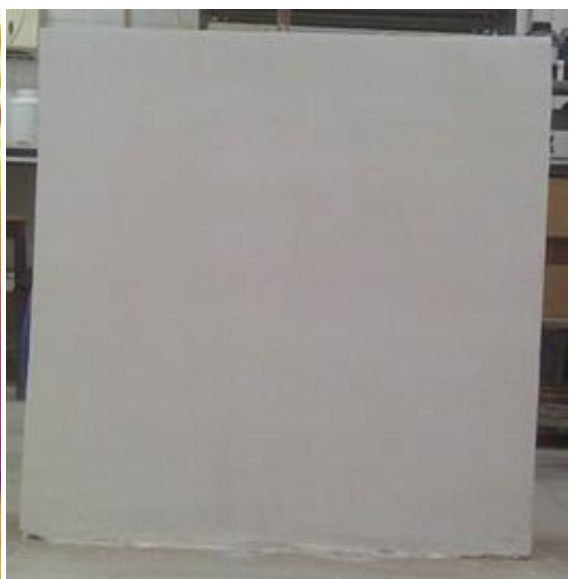

(b)
A porção umedecida ficou mais evidente no termograma do que na imagem convencional, além de mostrar uma delimitação clara dos componentes da alvenaria (tijolos e argamassa) no caso de 48 horas. As áreas molhadas apareceram mais frias em razão de a evaporação ser mais intensa nessa região, corroborando com Barreira, Almeida e Delgado (2016), Melrinho (2014) e Oliveira (2013).

Uma semana após a interrupção do vazamento a termografia revelou que ainda existia água no interior do protótipo, apesar de a fotografia comum não aparentar (Figura 14b). Materiais porosos, a exemplo da argamassa e do bloco cerâmico, requerem mais tempo para secar devido à sua baixa condutividade térmica, propriedade relacionada com a inércia térmica (MELRINHO, 2014; WIGGENHAUSER, 2002).

O gráfico com as temperaturas superficiais dos pontos SP1, SP2, SP3, SP4 e SP5 e da temperatura ambiental está apresentado na Figura 15.

A partir do momento da abertura da torneira até seu fechamento as temperaturas apresentam-se próximas entre si, com exceção de SP1, que foi mais quente devido à água da torneira. A temperatura ambiente foi maior na maioria do tempo, em torno de $2{ }^{\circ} \mathrm{C}$. Ao fim de 1 semana foi possível notar tendência a equilíbrio térmico da parede com o ambiente.

\section{Parede C (revestida com gesso e tinta base látex)}

Quando ainda não havia começado a simulação do vazamento, o termograma capturado mostrava que não havia umidade de forma aparente no protótipo (Figura 16).

A mancha de água se tornou aparente aos 2 minutos e 28 segundos. A camada de tinta fez a mancha demorar mais a aparecer, se comparado com o protótipo sem revestimento (Parede $\mathrm{A}=50$ segundos) e com o protótipo revestido apenas com gesso (Parede $\mathrm{B}=1$ minuto e 9 segundos).

A Figura 17 apresenta as imagens térmicas capturadas no decurso de 5 minutos, 1 hora e 2 horas após a simulação do vazamento. Constatou-se que com o avanço da frente úmida as manchas de umidade não apresentaram um padrão de aparição em nenhum momento do ensaio.

Na Figura 18 apresentam-se os termogramas tomados após 48 horas e 1 semana do vazamento, observando-se um contraste térmico definido e gradual entre a área seca e a área úmida. Com a transferência de calor pelo mecanismo de convecção, as áreas afetadas pela umidade demoraram mais a aquecer se comparada com as áreas secas. Com o passar do tempo a mancha de água foi aumentando devido à estrutura porosa da parede, fato esperado e comprovado por Alam (2016).

O comportamento do protótipo revestido com gesso e pintado com tinta de base látex (Parede C) se assemelhou ao daquele revestido apenas com gesso (Parede B) nos aspectos térmicos e de umedecimento. O caráter poroso da tinta látex permitiu que houvesse evaporação. Como previsto, a função de proteção promovida pela tinta aumentou o tempo para o surgimento da água de forma aparente.

Os gradientes térmicos entre área úmida e seca com o passar do tempo, representados por SP4 e SP1, respectivamente, estão exibidos graficamente na Figura 19.

O contraste térmico indicado na leitura realizada às 48 horas foi bastante significativo, sendo o maior do período de ensaio $\left(\Delta \mathrm{T}=3,0^{\circ} \mathrm{C}\right)$. $\mathrm{O}$ menor valor de $\Delta \mathrm{T}\left(-0,1^{\circ} \mathrm{C}\right)$ ocorreu quando a parede estava seca, por ser mínima a discrepância de temperatura entre 
os pontos analisados. A entrada de água mais quente que a parede explica a origem de valores de $\Delta \mathrm{T}$ negativos.
No gráfico representado na Figura 20 encontram-se as temperaturas superficiais dos pontos SP1, SP2, SP3, SP4 e SP5 e a temperatura do ambiente da Parede $\mathrm{C}$ ao longo do tempo.

Figura 15 - Temperaturas ambiente e dos pontos estudados para a Parede B

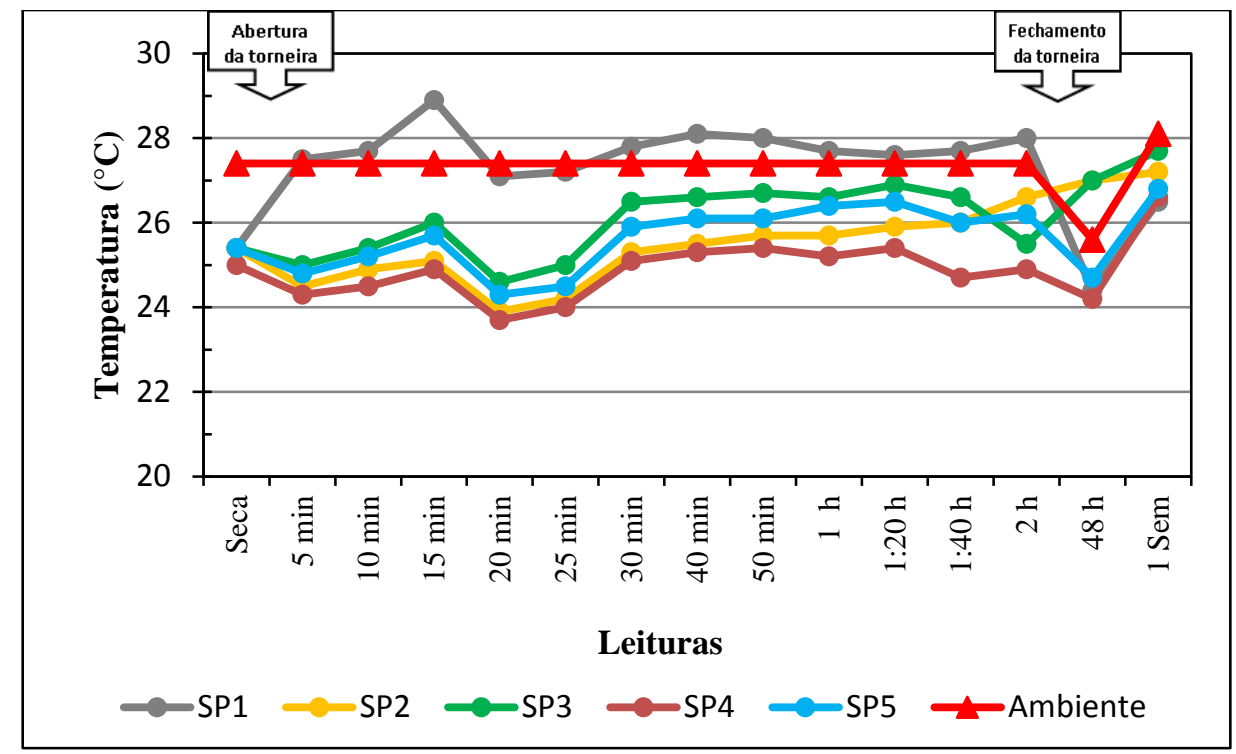

Figura 16 - Parede C seca: (a) termograma; (b) fotografia

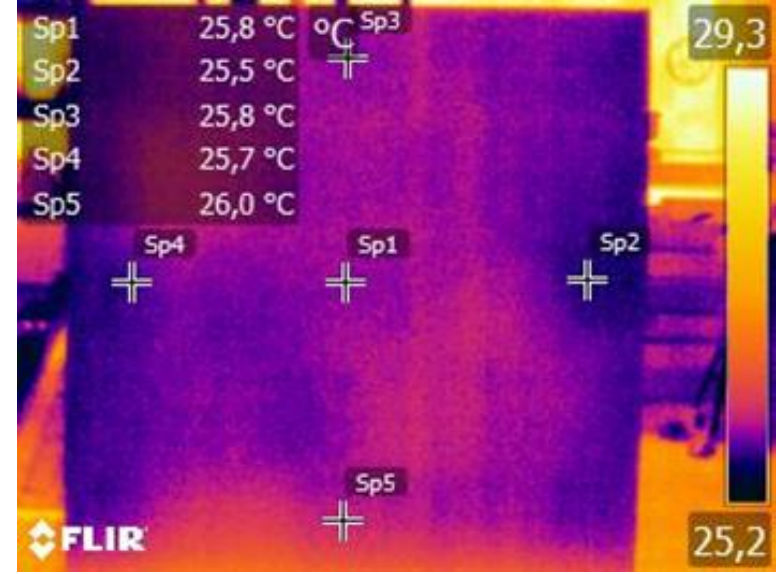

(a)

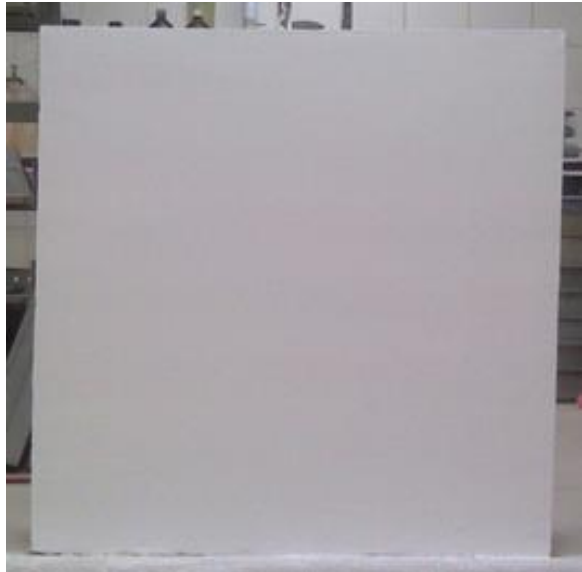

(b)

Figura 17 - Termogramas capturados durante o período em que a torneira estava aberta na Parede C: (a) 5 minutos; (b) 1 hora; (c) 2 horas

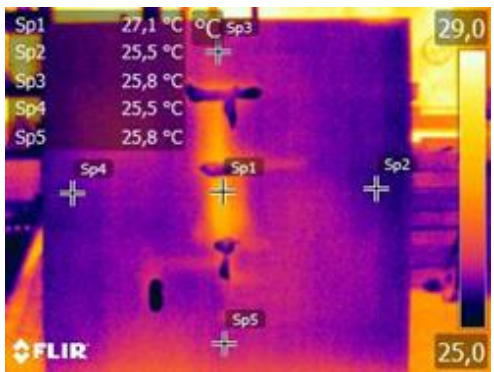

(a)

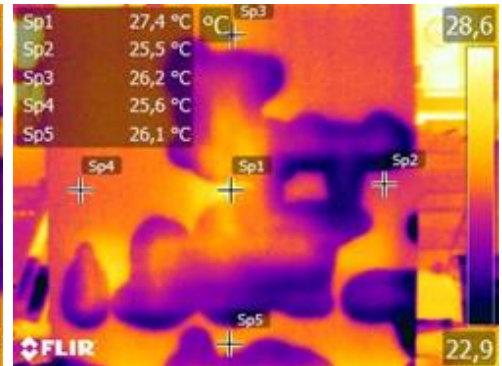

(b)

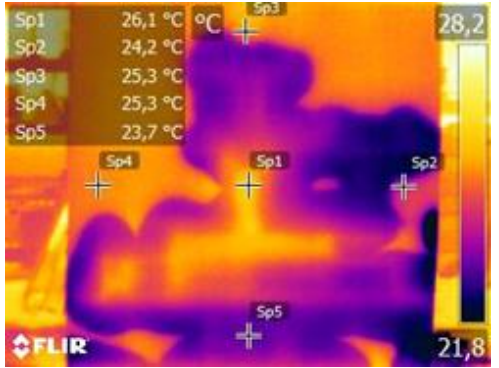

(c) 
Figura 18 - Leitura após inserção da água na Parede C: (a) 48 horas; (b) 1 semana

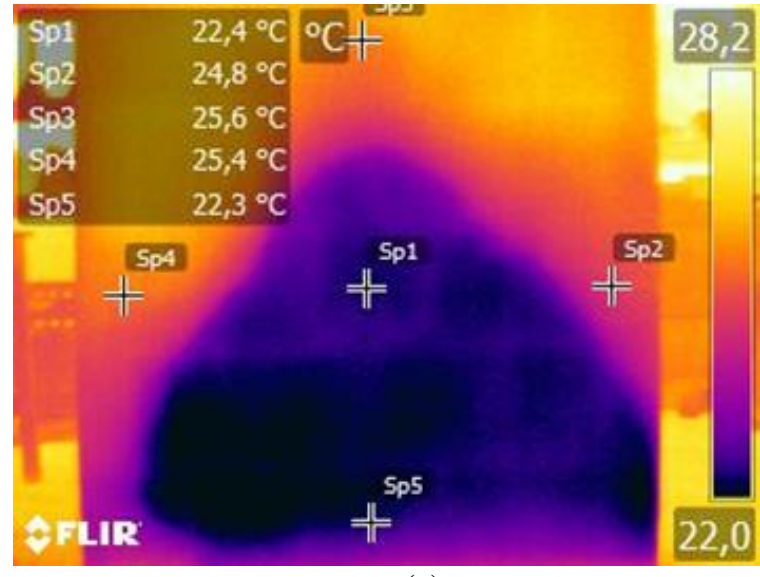

(a)

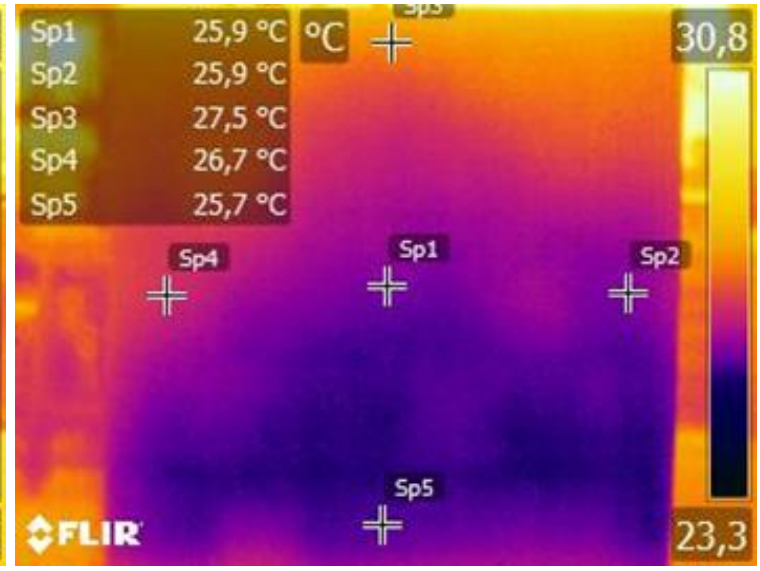

(b)

Figura 19 - Diferença de temperatura entre "SP4" e "SP1" na Parede C

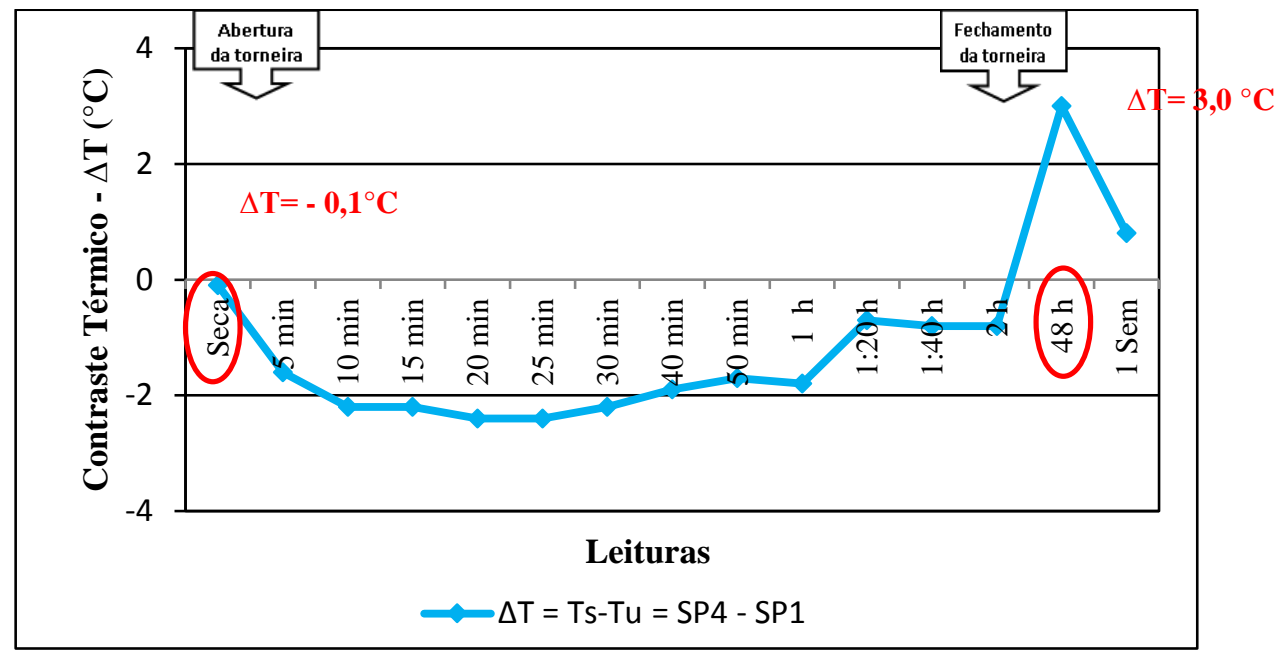

Figura 20 - Temperaturas ambiente e dos pontos SP1, SP2, SP3, SP4 e SP5 para a Parede C

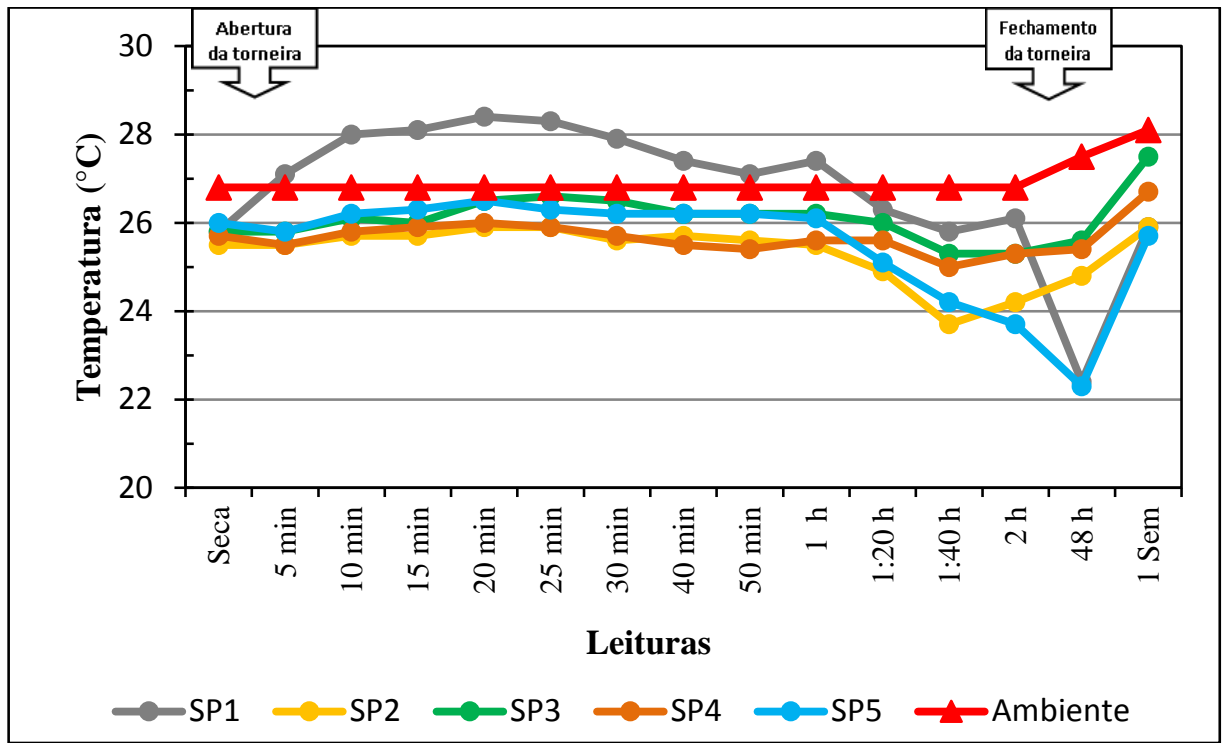


As temperaturas dos pontos se mantiveram próximas à temperatura ambiental, a exceção do SP1, em que ocorreu uma leve queda depois de 1 hora de ensaio. Após 48 horas de inserção da água houve uma diminuição na temperatura de SP1 e SP5, enquanto o restante se elevou. Acompanhando o crescimento da temperatura do ambiente, todas as temperaturas cresceram na ocasião da leitura realizada com 1 semana com a secagem do material.

\section{Parede D (revestida com gesso e tinta base acrílica)}

Antes da inserção da água as temperaturas de SP1, SP2, SP3, SP4 e SP5 apresentaram pouca variação entre si, com valor máximo em SP2 $\left(26,3{ }^{\circ} \mathrm{C}\right)$ e mínimo em SP4 $\left(25,8^{\circ} \mathrm{C}\right)$, isto é, com amplitude de $0,5^{\circ} \mathrm{C}$ (SP2-SP4), conforme pode ser observado no termograma (Figura 21a). A parede estava praticamente seca, exceto no quadrante inferior esquerdo da imagem térmica que apresentava mais umidade.
Na Figura 22 são apresentadas as imagens térmicas capturadas aos 5 minutos, 1 hora e 2 horas, após a colocação de água. Foi possível ver claramente a ação da água no interior do protótipo nos primeiros 5 minutos. Decorridas 1 e 2 horas após o início do teste, houve um espalhamento da água iniciado por meio da argamassa, conforme ocorreu com Cabaça (2002). É importante mencionar que as fotografias digitais não mostraram manchas de umidade em nenhum momento. Como a água não aflorou na superfície da parede resfriada pelo ambiente, nos termogramas não apareceram áreas frias (roxas) afetadas pela umidade, apenas a água aquecida que estava confinada.

A Figura 23 mostra os gradientes de temperatura entre a área seca (SP3) e a afetada pela água (SP1). No intervalo de 2 horas de ensaio o pico de $\Delta \mathrm{T}(-2,2$ ${ }^{\circ} \mathrm{C}$ ) ocorreu aos 15 minutos. Após as 48 horas foi possível observar um baixo valor de $\Delta \mathrm{T}\left(0,7^{\circ} \mathrm{C}\right)$. Em 1 semana o contraste térmico entre SP1 e SP2 cresceu, concluindo o experimento com um valor de $1,1^{\circ} \mathrm{C}$.

Figura 21 - Parede D seca: (a) termograma; (b) fotografia

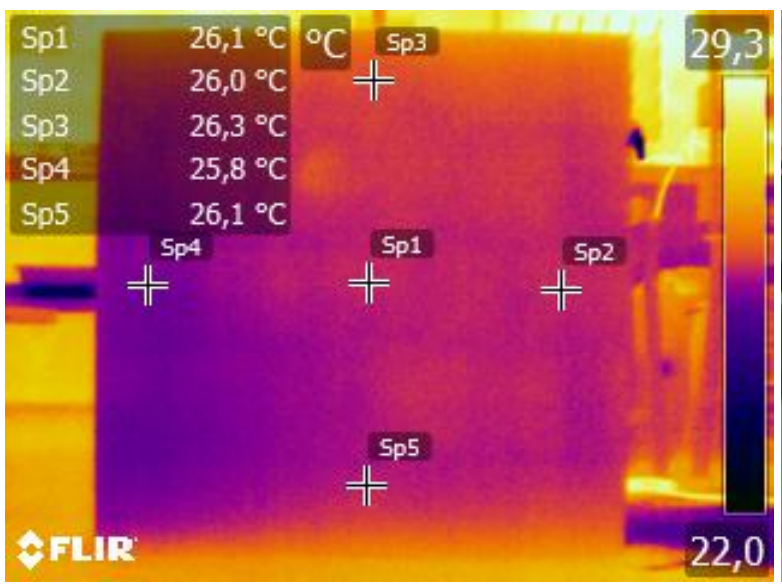

(a)

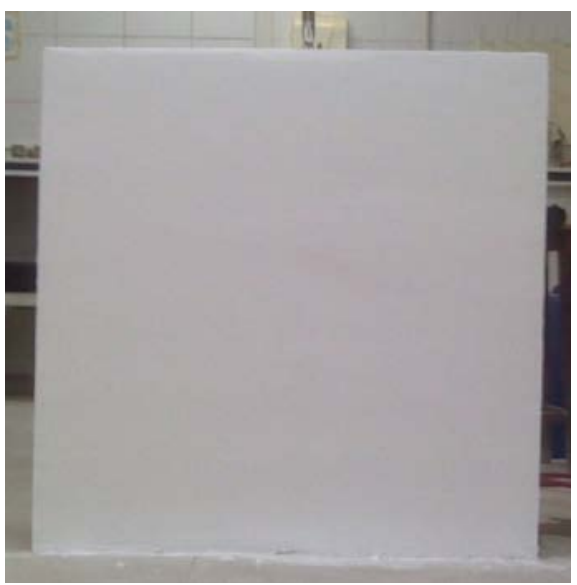

(b)

Figura 22 - Termogramas capturados durante o período em que a torneira estava aberta na Parede D: (a) 5 minutos; (b) 1 hora; (c) 2 horas

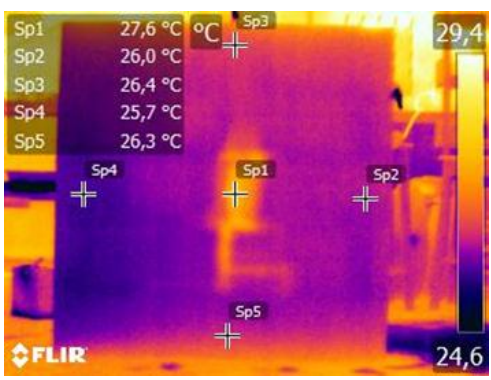

(a)

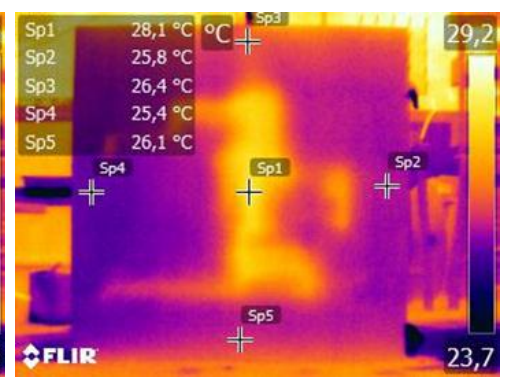

(b)

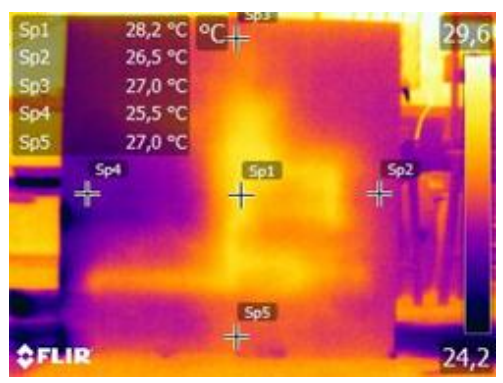

(c) 
Figura 23 - Diferença de temperatura entre "SP3" e "SP1" na Parede D

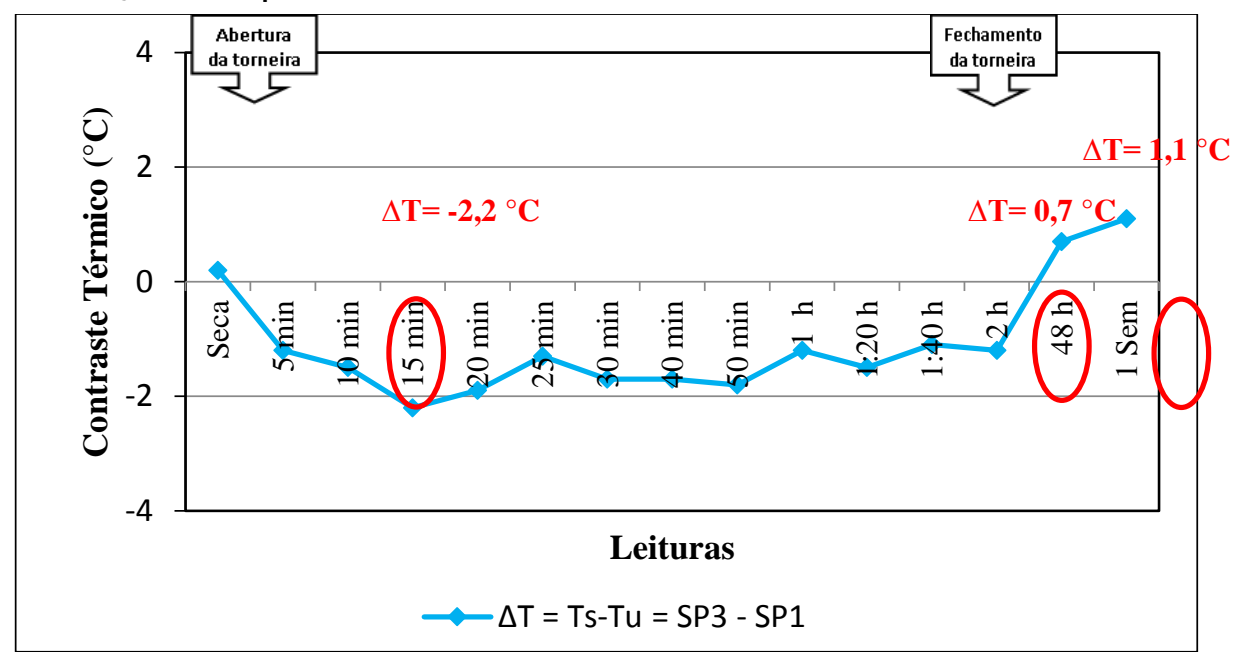

O termograma capturado às 48 horas (Figura 24a) mostrou que houve indícios de umidade na região inferior da parede, ficando a nitidez da detecção do foco da infiltração comprometida devido ao pequeno contraste térmico desenvolvido. Isso possivelmente ocorreu devido à presença da tinta acrílica, que formou uma fina camada praticamente impermeável, o que dificultou a evaporação da água próxima à superfície, processo que foi detectado pela termografia e confirmado por Oliveira (2013), além de fazer com que a água se espalhasse sobre o lado interno da camada de tinta. Na leitura de 1 semana houve aumento na temperatura ambiente devido a um problema no ar-condicionado, o que pôde ter facilitado o crescimento do contraste térmico que se apresentou no termograma da Figura 24b. A diferença térmica se apresentou de forma difusa, mas mesmo assim conseguiu estimar a localização da região na qual a infiltração havia começado.

Segundo Edis, Flores-Colen e Brito (2014), na maioria dos estudos para detecção de problemas de umidade por termografia em materiais porosos o fenômeno físico que impulsiona a investigação é o resfriamento evaporativo. No caso de fachadas com cerâmica onde a evaporação é dificultada pelo esmalte da placa, o resfriamento evaporativo na zona úmida não pode atuar como força motriz. Pode-se então usar a capacidade de armazenamento de calor da massa úmida como força motriz. Seguindo esse raciocínio, com a dificuldade de evaporação provocada pela tinta acrílica, pode-se recorrer também à capacidade de armazenamento de calor do material úmido na apreciação dos resultados, além de fazer a análise sob a ótica do fenômeno da diminuição da resistência térmica em um material úmido.

As temperaturas superficiais de SP1, SP2, SP3, SP4 e SP5 e a temperatura ambiental ao longo do tempo estão apresentados graficamente na Figura 25.

Durante as 2 horas de ensaios, devido à água quente da torneira, SP1 apresentou temperatura maior que o restante dos pontos. SP2, SP3, SP4 e SP5 tiveram temperaturas próximas à do ambiente e variaram pouco com o tempo. Após 48 horas 0 comportamento térmico foi diferente dos protótipos anteriores que apresentaram considerável discrepância térmica entre as áreas secas e aquelas afetadas pela umidade. Ao fim de 1 semana o equilíbrio térmico da parede com o ambiente tendeu a surgir.

\section{Parede E (revestida com gesso mais placa cerâmica assentada com gesso cola)}

Na Figura 26 evidencia-se que antes da inserção da água na parede as temperaturas superficiais de SP1 até SP5 estavam dentro de uma pequena faixa de variação de temperatura, indicando uma superfície uniforme e sem problemas. 
Figura 24 - Leitura realizada após a inserção de água na Parede D: (a) 48 horas; (b) 1 semana

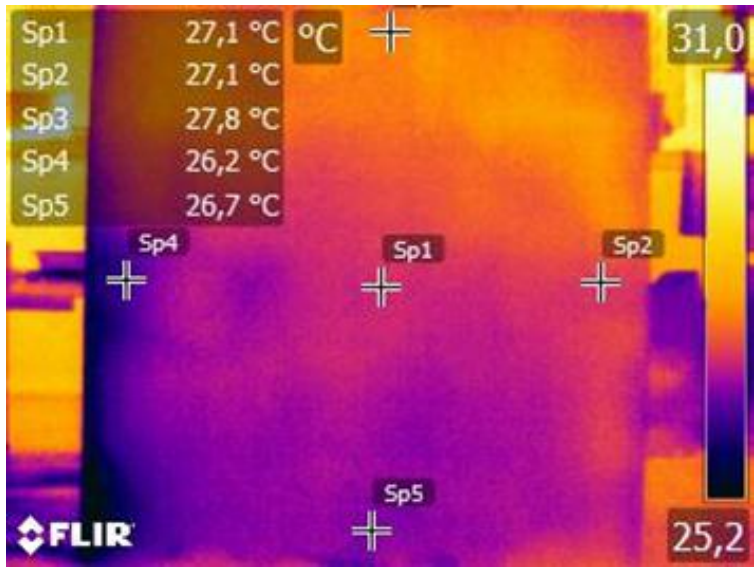

(a)

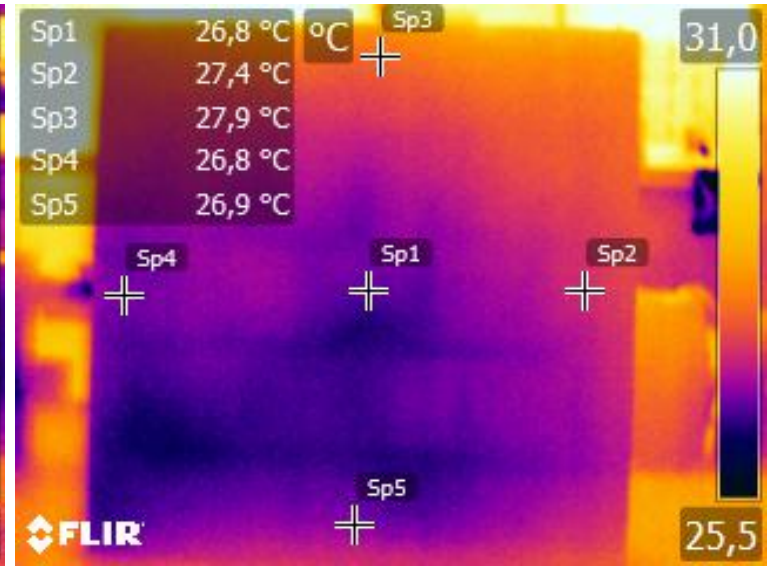

(b)

Figura 25 - Temperaturas ambiente e dos pontos SP1, SP2, SP3, SP4 e SP5 para a Parede D

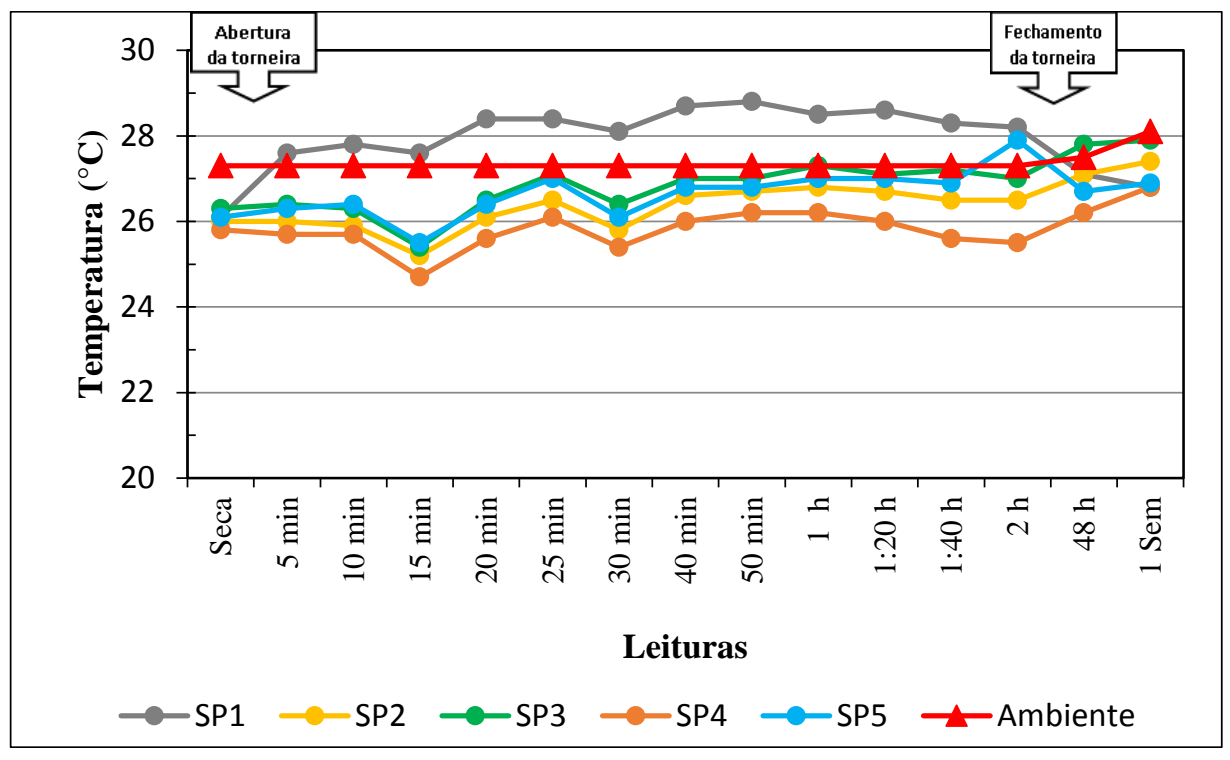

Figura 26 - Parede E seca: (a) termograma; (b) fotografia

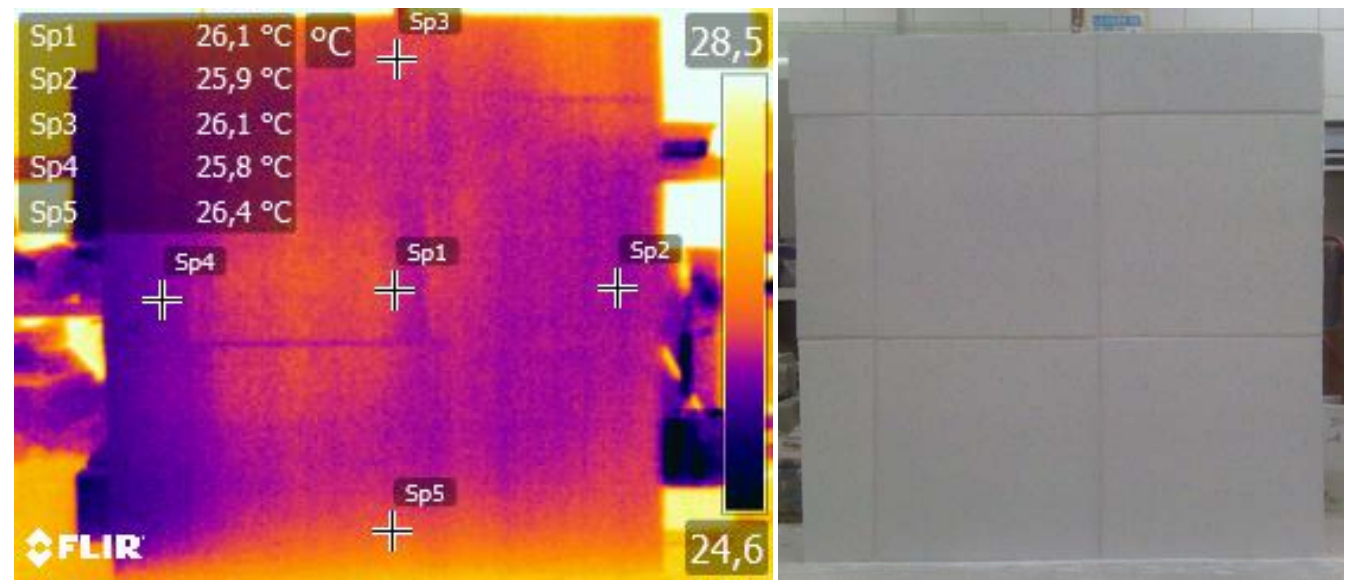

(a)

(b) 
Percebeu-se no termograma capturado, depois de 5 minutos (Figura 27a), maior emissão de radiação na região afetada pela umidade, que se deveu ao fato de a água estar mais quente do que a alvenaria, mudando a inércia térmica do material (MELRINHO; MATIAS; FARIA, 2015). Percebeu-se em 1 hora de ensaio mudanças no caminho percorrido pelo fluxo da água sem ocorrência de zonas mais frias (Figura 27b), uma vez que a água estava confinada, não evaporando para a parte superficial do protótipo, devido à presença do revestimento cerâmico. Não ficou explícito o local que continha o orifício na tubulação. Ao término das 2 horas de experimento o comportamento de avanço da infiltração continuou parecido (Figura 27c). Houve a formação de uma mancha generalizada na parte inferior do protótipo, o que dificultou a locação do furo que originou o vazamento. As fotografias não apresentaram nenhum sinal da presença de umidade durante todo o tempo do ensaio.
Os valores dos gradientes térmicos gerados durante o período de ensaio podem ser visualizados na Figura 28, na qual SP2 foi eleito para representar as áreas secas, e SP1 as úmidas.

Tal qual a Parede $\mathrm{D}$, as maiores diferenças de temperatura aconteceram durante o período em que a água estava incidindo na alvenaria, sendo fortemente influenciada pelo uso da água aquecida $\operatorname{com}$ pico $\left(\Delta \mathrm{T}=-1,7^{\circ} \mathrm{C}\right)$ aos 40 minutos. As leituras realizadas após as 48 horas e 1 semana apresentaram uma queda brusca, com $\Delta \mathrm{T}=0,2{ }^{\circ} \mathrm{C}$ e $\Delta \mathrm{T}=0{ }^{\circ} \mathrm{C}$, respectivamente.

Como o material foi aquecido apenas pela temperatura ambiental, gerando um $\Delta \mathrm{T}$ pequeno, às 48 horas e 1 semana a nitidez na visualização das áreas afetadas pela umidade (SP1 e SP5) não foi tão clara (Figura 29). Outro motivo para essa dificuldade foi a presença de revestimento cerâmico, pois impediu que a detecção da radiação emitida pela parede fosse captada de forma direta pelo equipamento, ratificado por Rocha et al. (2018).

Figura 27 - Termogramas capturados durante o período em que a torneira estava aberta na Parede E: (a) 5 minutos; (b) 1 hora; (c) 2 horas

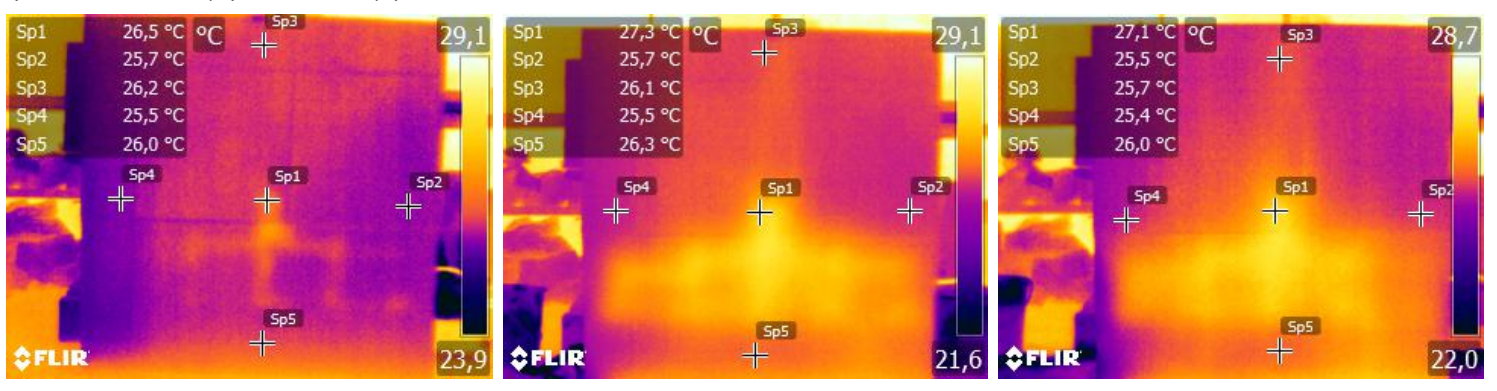

Figura 28 - Diferença de temperatura entre "SP2" e "SP1" na Parede E

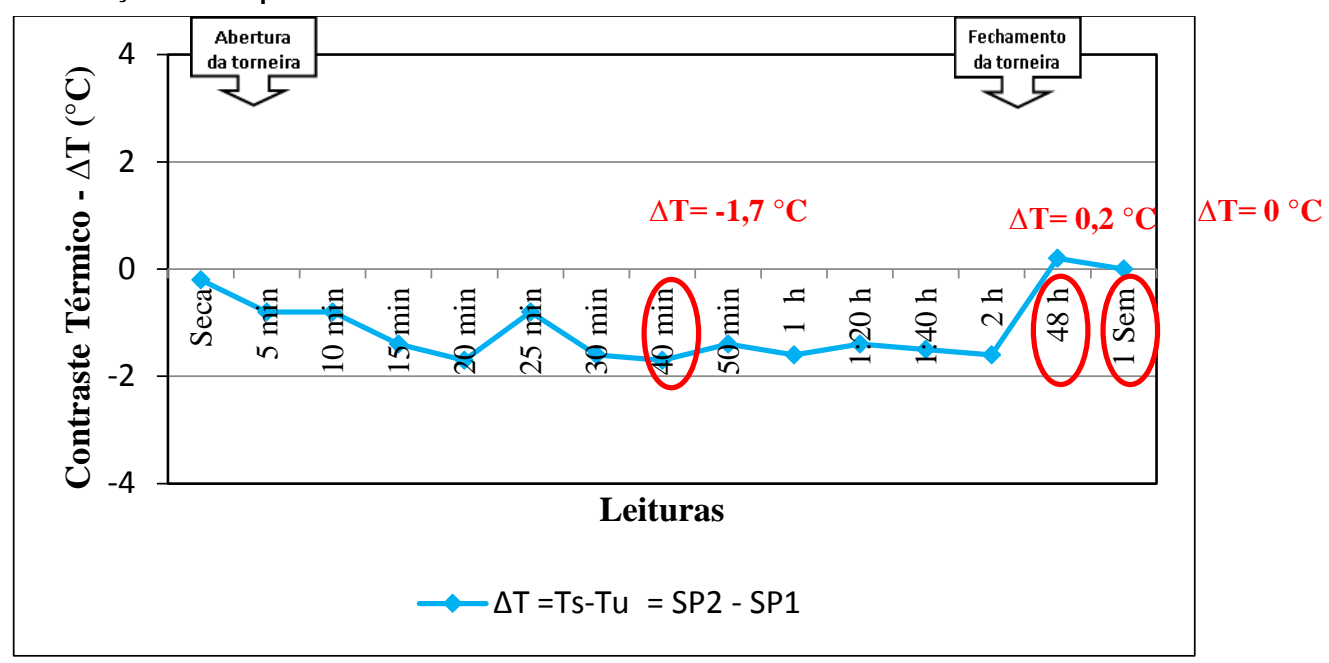


Figura 29 - Leitura realizada coma inserção de água na Parede E: (a) 48 horas; (b) 1 semana

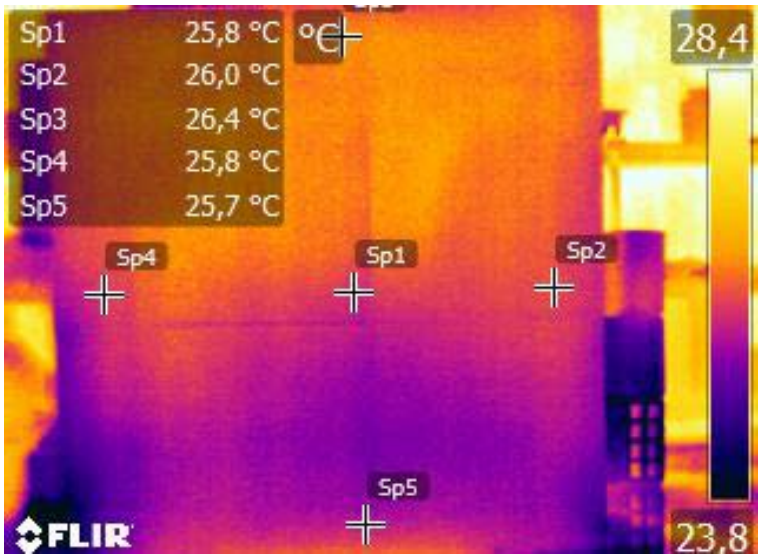

(a)

Lourenço, Matias e Faria (2017) provaram que é possível a detecção de umidade em revestimento cerâmico utilizando a termografia infravermelha, no entanto dois fatores tornam a detectabilidade nesse tipo de revestimento diferente de outros: primeiro a presença de vários componentes com suas características próprias, e segundo a baixa absorção de água de alguns tipos de placas cerâmicas que dificultam a presença de umidade dentro desse elemento. Contudo, utilizaram uma fonte de aquecimento para induzir o aparecimento de uma zona de refrigeração abaixo do revestimento, o que facilitou a detecção de áreas úmidas.

No presente estudo foi possível a detecção na etapa da secagem, mas com valores de gradientes baixos, pelo fato de o protótipo estar localizado em um ambiente interno; no entanto, para ter melhores resultados, poderia ser usada uma fonte de aquecimento, assim como Lourenço, Matias e Faria (2017) e Edis, Flores-Colen e Brito (2014), que utilizaram os raios solares para a geração de diferenças térmicas. Outro aspecto facilitador seria o uso de uma cerâmica semiporosa (absorção de água entre 6\% e 10\%), além do gesso cola utilizado para o assentamento da cerâmica e a argamassa de rejunte que não apresentam características hidrofugantes.

Em nenhum momento do ensaio a fotografia tradicional do protótipo revestido com cerâmica mostrou manchas d'água. Devido à presença de um revestimento impermeável, a detecção da região que continha a falha que originou o vazamento foi dificultada, principalmente nos momentos de leitura em que a torneira estava desligada, ou seja, 48 horas e 1 semana após o início do ensaio.

A Figura 30 apresenta o gráfico contendo as temperaturas superficiais ao longo do tempo de

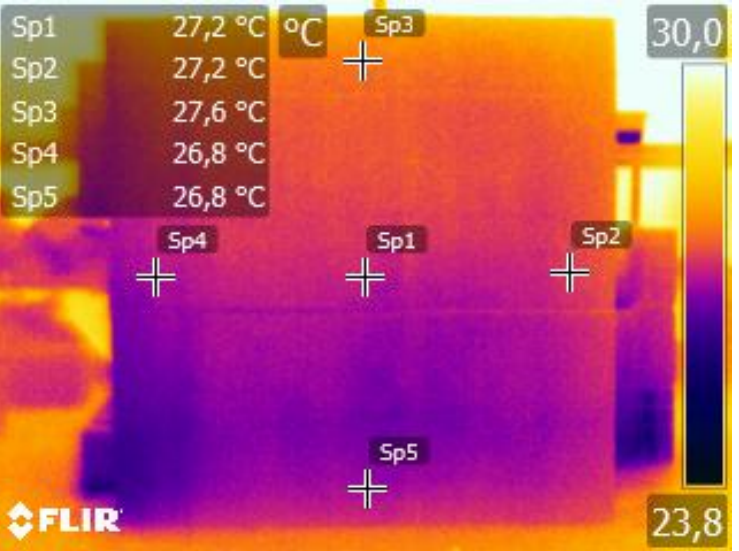

(b)

SP1, SP2, SP3, SP4 e SP5, além da temperatura ambiental.

Desde a condição seca da parede até o fim de 1 semana de ensaio, as temperaturas de todos os pontos, exceto SP1, que estava próximo da temperatura ambiente, mantiveram-se idênticas. Após 48 horas, com uma diminuição da temperatura do ambiente, houve um leve arrefecimento em SP1 e SP5, ao contrário das áreas secas que aqueceram. Após 1 semana todas as temperaturas aumentaram juntamente com a temperatura ambiental, tendendo a um equilíbrio térmico.

\section{Análise dos valores de contraste térmico dos protótipos}

O Quadro 5 apresenta os aspectos relacionados ao contraste térmico dos protótipos.

Observa-se que as paredes revestidas com material poroso apresentaram os maiores contrastes térmicos devido à facilidade de ocorrência do fenômeno de evaporação, enquanto os protótipos revestidos com material impermeável apresentaram baixos gradientes térmicos, dificultando a detecção da umidade. O uso da água aquecida fez com que fossem produzidos valores de $\Delta \mathrm{T}$ negativos. Desconsiderando a influência da água quente, percebe-se que essa diferença térmica de acordo com o tipo de revestimento fica mais perceptível.

O Quadro 6 apresenta os termogramas capturados com 2 horas, 48 horas e 1 semana para os protótipos estudados, nos quais é possível analisar de forma visual os fatos discutidos anteriormente.

\section{Considerações finais}

Na presente pesquisa foi desenvolvido um estudo experimental como objetivo de analisar a viabilidade da termografia passiva como ferramenta 
para a detecção de infiltração devido a causas fortuitas em paredes internas. Para tal motivo foram confeccionados 5 protótipos de tijolo cerâmico com vários tipos de revestimentos e inserção de tubulação de PVC furada para simular o vazamento.

Constatou-se que fatores como a secagem do material e o uso de revestimento impermeável podem afetar a formação de contrastes térmicos entre áreas secas e úmidas, limitando a eficiência da técnica. Entretanto, em muitos momentos a ação da água no interior da parede foi mostrada de forma nítida, enquanto a fotografia convencional não aparentava mancha de umidade em sua superfície, o que indica a potencialidade do método para inspeções de anomalias ainda em sua fase inicial.

Diante dos resultados, conclui-se que a análise termográfica pode ser bastante útil na identificação de problemas ocultos relacionados com a umidade acidental em edificações, desde que existam valores significativos de gradientes térmicos entre áreas secas e úmidas. No entanto, também foram detectadas áreas afetadas com valores em torno de $0,2^{\circ} \mathrm{C}$.

Figura 30 - Temperaturas ambiente e dos pontos SP1, SP2, SP3, SP4 e SP5 para a Parede E

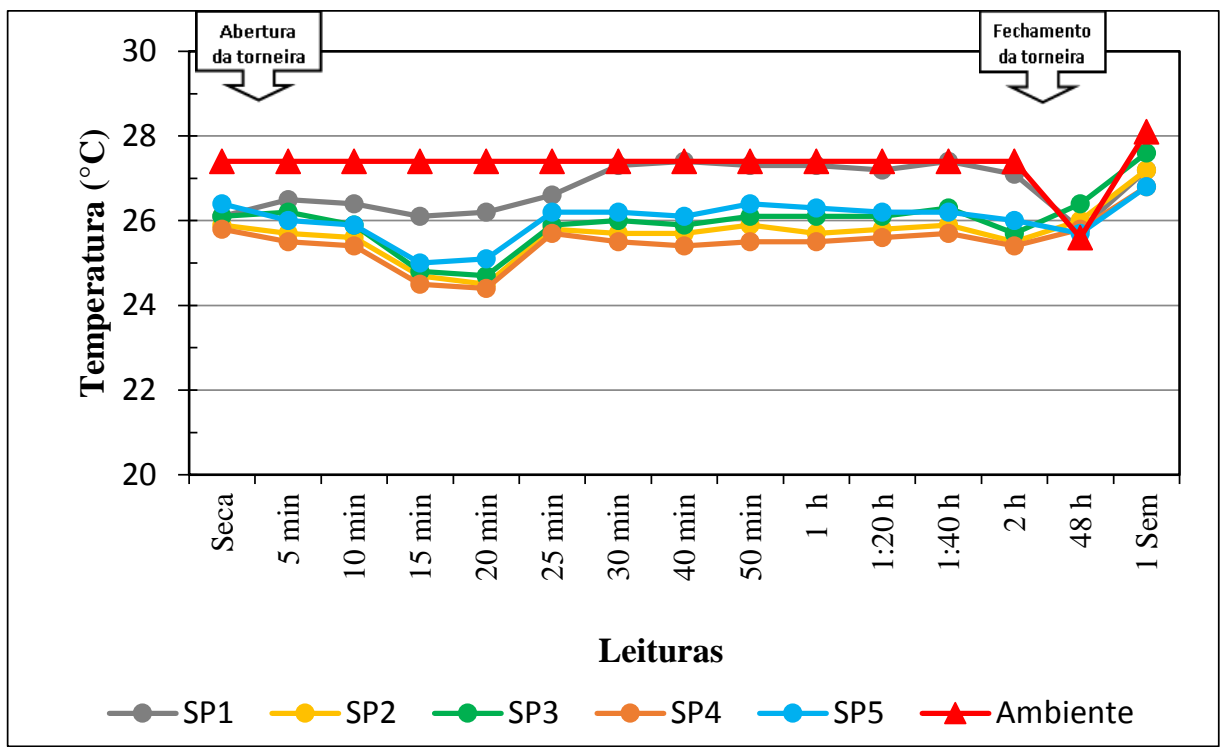

Quadro 5 - Informações sobre os contrastes térmicos dos protótipos

\begin{tabular}{|c|c|c|c|c|c|c|}
\hline \multirow{2}{*}{ Protótipo } & \multicolumn{3}{|c|}{$\mid \Delta \mathrm{T}$ máximo $\mid$} & \multicolumn{3}{|c|}{$\begin{array}{c}\Delta \text { T máximo sem a influência da água } \\
\text { aquecida }\end{array}$} \\
\hline & $\left({ }^{\circ} \mathrm{C}\right)$ & $\begin{array}{l}\text { Momento de } \\
\text { ocorrência }\end{array}$ & Nota & $\left({ }^{\circ} \mathrm{C}\right)$ & $\begin{array}{l}\text { Momento de } \\
\text { ocorrência }\end{array}$ & $\begin{array}{r}\text { Temperatura } \\
\text { ambiente }\left({ }^{\circ} \mathrm{C}\right)\end{array}$ \\
\hline Parede A & 3,2 & $\begin{array}{l}48 \text { horas após a } \\
\text { inserção de água }\end{array}$ & - & 3,2 & $\begin{array}{l}48 \text { horas após a } \\
\text { inserção de água }\end{array}$ & 27,5 \\
\hline Parede B & 3,8 & $\begin{array}{l}15 \text { minutos após a } \\
\text { inserção de água }\end{array}$ & $\begin{array}{c}\Delta \mathrm{T} \\
\text { negativo }\end{array}$ & 2,6 & $\begin{array}{l}48 \text { horas após a } \\
\text { inserção de água }\end{array}$ & 25,6 \\
\hline Parede C & 3,0 & $\begin{array}{l}48 \text { horas após a } \\
\text { inserção de água }\end{array}$ & - & 3,0 & $\begin{array}{l}48 \text { horas após a } \\
\text { inserção de água }\end{array}$ & 27,5 \\
\hline Parede D & 2,2 & $\begin{array}{l}15 \text { minutos após a } \\
\text { inserção de água }\end{array}$ & $\begin{array}{c}\Delta \mathrm{T} \\
\text { negativo }\end{array}$ & 1,1 & $\begin{array}{l}\text { 1 semana após a } \\
\text { inserção de água }\end{array}$ & 28,1 \\
\hline Parede E & 1,7 & $\begin{array}{l}40 \text { minutos após a } \\
\text { inserção de água }\end{array}$ & $\begin{array}{c}\Delta \mathrm{T} \\
\text { negativo }\end{array}$ & 0,2 & $\begin{array}{l}48 \text { horas após a } \\
\text { inserção de água }\end{array}$ & 25,6 \\
\hline
\end{tabular}


Quadro 6 - Termogramas capturados com 2 horas, 48 horas e 1 semana para os protótipos estudados

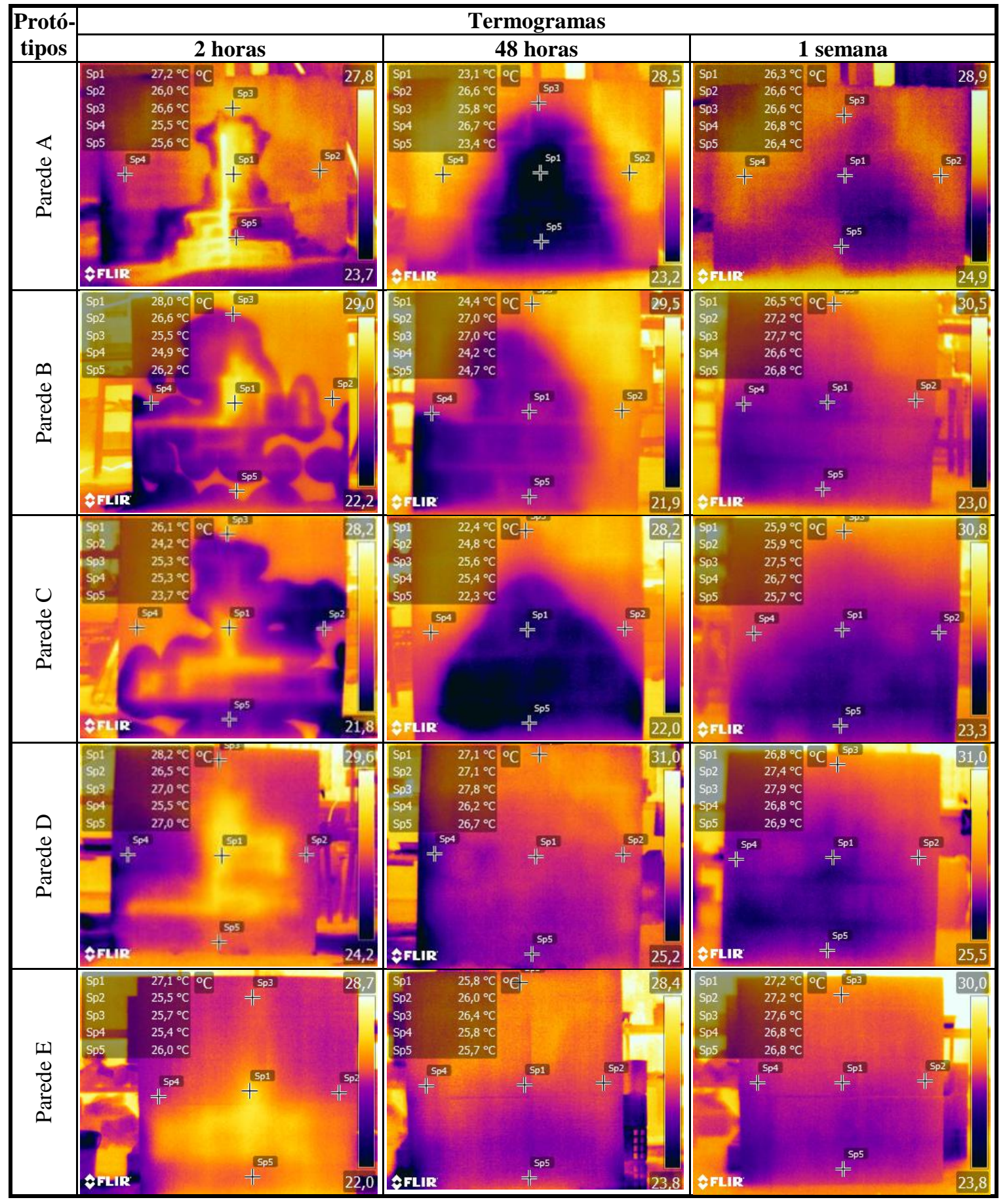

A detecção da infiltração com a termografia foi fortemente influenciada pelo tipo de revestimento. As paredes revestidas com material mais poroso apresentaram melhores resultados, devido aos maiores valores de gradientes térmicos, próximo de $4{ }^{\circ} \mathrm{C}$. Esse tipo de revestimento permitiu a evaporação do vapor de água, fenômeno que causa heterogeneidade no material, influenciando o resultado apresentado pela câmera termográfica. Nos revestimentos com características impermeáveis, devido à limitação da evaporação, houve dificuldade na detecção, fato que pode ser confirmado com valores de $\Delta \mathrm{T}$ com valor máximo de $2,2{ }^{\circ} \mathrm{C}$.

Os resultados obtidos foram bastante encorajadores para a adoção da termografia infravermelha como ferramenta auxiliar nas inspeções de obras civis, especialmente nos problemas relacionados com a presença de umidade nas construções, anomalia bastante comum. Embora a técnica venha se 
mostrando bastante eficiente, a falta de padronização de procedimentos em relação às infiltrações (ao contrário de outros setores) sugere o seu uso, por enquanto, em caráter complementar com a análise visual e outros métodos.

\section{Referências}

AGGELIS, D. et al. Combined Use of Thermography and Ultrasound For the Characterization of Subsurface Cracks in Concrete. Construction and Building Materials, v. 24, n. 10, p. 1888-1897, 2010.

ALAM, F. W, A. Potencialidade da Termografia na Detecção de Manifestações Patológicas Associadas à Umidade Acidental. Pelotas, 2016. 146 f. Dissertação (Mestrado em Engneharia Civil) - Faculdade de Arquitetura e Urbanismo, Universidade Federal de Pelotas, Pelotas, 2016.

AMARANTE, H. M. S; PONTES, J. C. A. de; MICHALOSKI, A. O. Termografia na Prevenção de Acidentes no Sistema Elétrico de Potência. Revista Espacios, v. 37, n. 23, p. 24, 2016.

ASSOCIAÇÃO BRASILEIRA DE NORMAS TÉCNICAS. NBR 15270-1: componentes cerâmicos: parte 1: blocos cerâmicos para alvenaria de vedação: terminologia e requisitos. Rio de Janeiro, 2005a.

\section{ASSOCIAÇÃO BRASILEIRA DE NORMAS TÉCNICAS. NBR 15270-3: componentes cerâmicos: parte 3: blocos cerâmicos para alvenaria estrutural e de vedação: método de ensaio. Rio de Janeiro, 2005b.}

BAGAVATHIAPPAN, S. et al. Infrared Thermography For Condition Monitoring: a review. Infrared Physics \& Technology, v. 60, n. 1, p. 35-55, 2013.

BARREIRA, E. Aplicação da Termografia ao Estudo do Comportamento Higrotérmico dos Edifícios. Porto, 2004. 183 f. Dissertação (Mestrado em Engenharia Civil) - Faculdade de Engenharia, Universidade do Porto, Porto, 2004.

BARREIRA, E.; ALMEIDA, R. M. S. F.; DELGADO, J. M. P. Q. Infrared Thermography For Assessing Moisture Related Phenomena in Building Components. Construction and Building Materials, v. 110, p. 251-269, 2016.

BARREIRA, E.; ALMEIDA, R. M. S. F.; MOREIRA, M. An Infrared Thermography Passive Approach to Assess the Effect of Leakage Points in Buildings. Energy and Buildings, v. 140, p.224-235, 2017.

BARREIRA, E.; FREITAS, V. P. de. Evaluation of Building Materials Using Infrared
Thermography. Construction and Building Materials, v. 21, n. 1, p. 218-224, 2007.

BAUER, E.; PAVÓN, E. Análise da Fissuração de Revestimento em Argamassa Com Emprego da Termografia de Infravermelho. In: SIMPÓSIO BRASILEIRO DE TECNOLOGIA DAS ARGAMASSAS, 12., São Paulo, 2017. Anais... Porto Alegre: ANTAC, 2017.

BAUER, E. et al. Analysis of Building Facade Defects Using Infrared Thermography: laboratory studies. Journal of Building Engineering, v. 6, p. 93-104, 2016.

BERNARDO, G. da. S. R. L. Técnicas Avançadas de Controlo Não Destrutivo Para Ligações de Ligas Com Memória de Forma a Aços de Construção Civil. Lisboa, 2012. 116 f. Tese (Doutorado em Engenharia Civil) - Faculdade de Ciências e Tecnologia, Universidade Nova de Lisboa, Lisboa, 2012.

CABAÇA, S. Humidade Ascendente em Paredes de Edifícios Antigos. Processos de Reabilitação e Prevenção. Construlink, v. 9, 2002.

DE FREITAS, S. S.; DE FREITAS, V. P.; BARREIRA, E. Detection of Façade Plaster Detachments Using Infrared Thermography: a nondestructive technique. Construction and Building Materials, v. 70, p. 80-87, 2014.

EDIS, E.; FLORES-COLEN, I.; BRITO, J. de. Passive Thermographic Detection of Moisture Problems in Façades With Adhered Ceramic Cladding. Construction and Building Materials, v. 51, p. 187-197, 2014.

FERRARINI, G. et al. Thermal Response Measurement of Building Insulating Materials by Infrared Thermography. Energy and Buildings, v. 133, p. 559-564, 2016.

FLIR. User's Manual FLIR Exx Series. $1^{\text {st }}$. ed. Wilsonville: FLIR, 2013.

FREITAS, J. G. de; CARASEK, H.; CASCUDO, O. Utilização de Termografia Infravermelha Para Avaliação de Fissuras em Fachadas Com Revestimento de Argamassa e Pintura. Ambiente Construído, Porto Alegre, v. 14, n. 1, p. 57-73, jan./mar. 2014.

GRINZATO, E. et al. Infrared Thermography For Moisture Detection: a laboratory study and in-situ test. Materials Evaluation, v. 69, n. 1, p. 97-104, 2011.

HAM, Y.; GOLPARVAR-FARD, M. 3D

Visualization of Thermal Resistance and 
Condensation Problems Using Infrared Thermography For Building Energy Diagnostics. Visualization in Engineering, v. 2, n. 1, p. 12, 2014.

ISRAEL, M. C. Ensaios Não Destrutivos Aplicados à Avaliação de Revestimentos de Argamassa. São Paulo, 2016. 167 f. Dissertação (Mestrado em Engenharia Civil) - Escola Politécnica, Universidade de São Paulo, São Paulo, 2016.

JONOV, C. M. P.; NASCIMENTO, N. de O.; PAULA E SILVA, A. de. Avaliação de danos às edificações causados por inundações e obtenção dos custos de recuperação. Ambiente Construído, Porto Alegre, v. 13, n. 3, p. 75-94, jul./set. 2013.

KLÜPPEL, G. P.; SANTANA, M. C. de. Manual de Conservação Preventiva Para Edificações. Brasília: Programa Monumenta/IPHAN, 2005.

LERMA, J. L.; CABRELLES, M.; PORTALÉS, C. Multitemporal Thermal Analysis to Detect Moisture on a Building Façade. Construction and Building Materials, v. 25, n. 5, p. 2.190-2.197, 2011.

LOURENÇO, T.; MATIAS, L.; FARIA, P. Anomalies Detection in Adhesive Wall Tiling Systems by Infrared Thermography. Construction and Building Materials, v. 148, p. 419-428, 2017.

MARINHO, M. I. M. Diagnóstico de Patologias Associadas à Humidade Utilizando Técnicas Não Destrutivas. Porto, 2014. 160 f. Dissertação (Mestrado em Engenharia Civil) - Faculdade de Engenharia, Universidade do Porto, Porto, 2014.

MAROY, K. et al. On the Use of Infrared Thermographic Measurements For Evaluating the Airtightness of the Building Envelope. Recent Developments in Building Diagnosis Techniques, v. 5, p. 145-169, 2016.

MELRINHO, A. C. E. Anomalias em Impermeabilizações de Coberturas em Terraço: detecção por termografia de infravermelhos. Lisboa, 2014. 246 f. Dissertação (Mestrado em Engenharia Civil) - Faculdade de Ciências e Tecnologia, Universidade Nova de Lisboa, Lisboa, 2014.

MELRINHO, A.; MATIAS, L.; FARIA, P. Detecção de Anomalias em Impermeabilizações de Coberturas em Terraço Através da Termografia de Infravermelhos. TECH ITT, v. 13, n. 37, p. 29-38, 2015.
O’GRADY, M.; LECHOWSKA, A.; HARTE, A. Infrared Thermography Technique as in-situ Method of Assessing Heat Loss Through Thermal Bridging. Energy and Buildings, v. 135, p. 20-32, 2017.

OLIVEIRA, G. F. P. de. Potencialidades da Termografia Para o Diagnóstico de Patologias Associadas à Humidade. Porto, 2013. 194 f. Dissertação (Mestrado em Engenharia Civil) Faculdade de Engenharia, Universidade do Porto, Porto, 2013.

ONUAGULUCHI, O.; BANTHIA, N. Infrared Thermographic Assessment of Cement Mortar Porosity and Strength. Journal of Civil

Structural Health Monitoring, v. 7, n. 3, p. 375384, 2017.

POBLETE, A.; PASCUAL, M. A. Thermographic Measurement of the Effect of Humidity in Mortar Porosity. Infrared Physics\& Technology, v. 49, n. 3, p. 224-227, 2007.

REHMAN, S. et al. Nondestructive Test Methods For Concrete Bridges: a review. Construction and Building Materials, v. 107, n. 15, p. 58-86, 2016.

ROCHA, J. H. A.; PÓVOAS, Y. V. A Termografia Infravermelha Como Um Ensaio Não Destrutivo Para a Inspeção de Pontes de Concreto Armado: Revisão do estado da arte. Revista Alconpat, v. 7, n. 3, p. 200-2014, 2017.

ROCHA, J. H. A. et al. Detecção de Infiltração em Áreas Internas de Edificações Com Termografia Infravermelha: estudo de caso. Ambiente Construído, Porto Alegre, v. 14, n. 4, p. 63-78, out./dez. 2018.

SILVA, D. D. S. da. Diagnóstico de Patologias em Fachadas Utilizando Termografia. Porto, 2012. 132 f. Dissertação (Mestrado em Engenharia Civil) - Faculdade de Engenharia, Universidade do Porto, Porto, 2012.

TARPANI, J. R. et al. Inspeção Termográfica de Danos Por Impacto em Laminados de Matriz Polimérica Reforçados Por Fibras de Carbono. Polímeros: Ciência e Tecnologia, v. 19, n. 4, p. 318-328, 2009.

WIGGENHAUSER, H. Active IR-Applications in Civil Engineering. Infrared Physics \&

Technology, v. 43, n. 3, p. 233-238, 2002. 


\section{Cynthia Firmino dos Santos}

Escola Politécnica | Universidade de Pernambuco | Rua Benfica, 455, Madalena | Recife - PE - Brasil | CEP 50720-001 | Tel.: (81) 31847566| E-mail: cynthia_civil@yahoo.com.br

\section{J oaquin Humberto Aquino Rocha}

Universidad Privada del Valle | Calle Guillermina Martínez, s/n | Cochabamba - Bolívia | Tel.: +591 (4) 431-8800 | E-mail: joaquinaquinorocha@gmail.com

\section{Yêda Vieira Póvoas}

Escola Politécnica | Universidade de Pernambuco | E-mail: yeda.povoas@gmail.com

\section{Revista Ambiente Construído}

Associação Nacional de Tecnologia do Ambiente Construído

Av. Osvaldo Aranha, 99 - 30 andar, Centro

Porto Alegre - RS - Brasil

$$
\text { CEP } 90035-190
$$

Telefone: +55 (51) 3308-4084

Fax: +55 (51) 3308-4054

www. seer. ufrgs. br/ ambienteconstruido

E-mail: ambienteconstruido@ufrgs.br 